\title{
EVALUATION OF MANGROVE REHABILITATION AFTER BEING DESTROYED BY CHEMICAL WARFARE USING REMOTE SENSING TECHNOLOGY: A CASE STUDY IN CAN GIO MANGROVE FOREST IN MEKONG DELTA, SOUTHERN VIETNAM
}

\author{
LAP, Q. K. ${ }^{1}-$ LUONG, V. N. ${ }^{2 *}-$ HONG, X. T. ${ }^{2}-$ TU, T. T. ${ }^{2}-$ THANH, K. T. P. ${ }^{2}$ \\ ${ }^{I}$ Thai Nguyen University of Sciences, Tan Thinh Ward, Thai Nguyen City 250000, Vietnam \\ ${ }^{2}$ Space Technology Institute, Vietnam Academy of Science and Technology, \\ 18 Hoang Quoc Viet str., Cau Giay dist., Hanoi 100000, Vietnam \\ *Corresponding author \\ e-mail: nvluong@sti.vast.vn; phone: +84-243-756-2985; fax:+84-243-791-4622
}

(Received 21 $1^{\text {st }}$ Apr 2021; accepted $12^{\text {th }}$ Aug 2021)

\begin{abstract}
In this study, we used satellite data (optical and radar) to evaluate mangrove rehabilitation in an area that has been completely destroyed by the use of herbicides and other chemical agents by the U.S military in the Can Gio Biosphere Reserve in Mekong Delta, Southern Vietnam. We used the Landsat satellite imagery series to analyse the land cover change, and the results showed that the coverage of the mangroves in this study area has gradually increased over the years: $9.54 \%$ in $1972,34.46 \%$ in 1988 , $46.34 \%$ in $1995,51.76 \%$ in $2000,54.27 \%$ in $2005,56.93 \%$ in $2010,59.91 \%$ in 2015 and $63.70 \%$ in 2020 . The overall accuracy is $92.76 \%$, and the average accuracy is $85.47 \%$. We used a combination of images taken from ALOS-2 PALSAR-2 and Landsat satellites to build models that detect the structural parameters of mangrove forests. These models can explain mangrove structural parameters such as the basal area of $91 \%\left(R^{2}=0.91\right)$, the height of $60 \%\left(R^{2}=0.60\right)$, the density of $52 \%\left(R^{2}=0.52\right)$ and the biomass of $91 \%\left(\mathrm{R}^{2}=0.91\right)$. This study aims to provide results to study area for better management, monitoring, conservation as well as sustainable development of mangrove forests.

Keywords: mangrove restoration, herbicide, spraying, U.A. air force, Landsat, ALOS-2 PALSAR-2, management, monitoring, conservation, sustainable development, UNESCO/MAB.
\end{abstract}

\section{Introduction}

Mangrove ecosystems cover a large part of wetland areas and are often distributed in the coasts of the tropical and subtropical regions (Rouse et al., 1974; Hong et al., 1988; Kuenzer et al., 2011; Salem et al., 2012). As a strictly limited habitat, true mangroves are home to about 50 species globally, which belong to 16 families. However, they have many useful functions for mankind (Marchand et al., 2008). The key products and services provided by the mangrove ecosystems include wood products (e.g., fibres, timber, fuelwood and charcoal), non-wood resources (e.g., food, fruits, wildlife, mariculture, capture fishery, honey, chemicals and medicine) and ecosystem and environmental services (e.g., extending the shorelines, coastal protection, eco-tourism, blue carbon storage and $\mathrm{CO}_{2}$ sequestration) (Lugo et al., 1974; Hong et a., 1999; Duke et al., 2007; Vo et al., 2015; Veettil et al., 2019). Thus, the mangrove ecosystem contributes significantly to the livelihoods, well-being and security of coastal communities (Donato et al., 2011; Murdiyarso et al., 2015; Giri, 2016; FAO, 2020).

The total area of mangroves in the world is estimated at between $138,000 \mathrm{~km}^{2}$ and $200,000 \mathrm{~km}^{2}$ and distributed among 128 countries and territories. However, mangroves 
are widely distributed mainly (approximately 75\%) in 15 countries (Duke et al., 2007; Salem et al., 2012; Giri, 2016; FAO, 2020), and more than $90 \%$ are located in the developing countries (Duke et al., 2007). Unfortunately, mangroves are now declining at alarming rates, even faster than inland tropical forests (Salem et al., 2012; Giri et al., 2007, 2016; Chen et al., 2019). According to Duke (2007), the rate of global mangrove loss is $1-2 \%$ per year (Duke et al., 2007). Up to about $80 \%$ of these human-driven losses occurred in Southeast Asia (Giesen et al., 2007; Goldberg et al., 2020; FAO, 2020). The main causes of mangrove forest decline are increased population pressure in the coastal areas; industrial zone developments in coastal areas; illegal felling; expansion in acreage for agriculture, urbanization and residential land; and shrimp farming (Duke et al., 2007; Salem et al., 2012; Murdiyarso et al., 2015; FAO, 2020).

The mangroves in Vietnam are divided into four main zones from North to South by geographical location and the Can Gio mangrove forest lies in the fourth zone, which has the most diverse species composition and size of mangroves. Vietnam has 36 true mangrove plant species (Hong et al., 1999). Currently, Vietnam has about 169,000 hectares of mangroves, a decrease of $60 \%$ as compared to the 1940s (MARD, 2015). South Vietnam mangrove forests occupy 250,000 ha, as reported by Cuong (1964), which are distributed as follows: Ca Mau Peninsula has 150,000 ha, the Can Gio and Phuoc Hoa region have 40,000 ha and the rest have 20,000 ha (Ross, 1974), it covers nearly $80 \%$ of the mangroves in Vietnam (Hong et al., 1999).

The mangrove ecosystem is being increasingly recognised and considered as a significant one while creating the goals for national and global development and environments, such as for sustainable development activities and agreement on climate change (Marchand et al., 2008; Murdiyarso et al., 2015; Giri, 2016; FAO, 2020).

Due to the unique nature of the role of mangrove ecosystems. So, over the past decades, many international organizations, investment funds, NGOs and countries have invested millions of dollars for the conservation and restoration of mangroves in the world, and they consider it as an important measure in coastal management (De Leon et al., 1999; Brown et al., 2014; Ha'apio et al., 2018; Hai et al., 2020). However, there have been many unsuccessful or failed projects on mangrove restoration in India (Lewis, 2005), the Philippines (Primavera et al., 2008), the Ha Tinh province of Vietnam (Hong, 1993), northern Vietnam (Seto et al., 2007), etc. This is due to many reasons, mainly that most of these mangrove restoration projects lack data to evaluate the long-term success of the project and even assess the natural conditions before project implementation (Marchand, 2008). This has led to unsuccessful and indirectly wasteful mangrove rehabilitation projects.

There is a growing need for detailed mangrove forest maps for good monitoring and management of mangrove ecosystems (Vaiphasa et al., 2006). However, a detailed mangrove map is not easy to develop because mangroves are difficult to access (Vaiphasa et al., 2006).

Today, there is increasing advancement in technology, satellites and sensors and more accessibility to remotely sensed data with high temporal and resolution imagery. Some of these are available for free, along with strong computer systems (hardware), image processing techniques and new classification algorithms (software) (Giri, 2016; Kuenzer et al., 2011; Pham et al., 2019; Pham et al., 2020). It can be affirmed that remote sensing is a perfect alternative to traditional mangrove mapping methods based entirely on the field because it allows information gathering from the forbidden 
environment of the mangrove forest, which otherwise, logically and practically, would be difficult to investigate (Vaiphasa et al., 2006).

Studies on the application of remote sensing data in mangrove ecosystems have been reviewed by authors such as Kuenzer et al. (2011), Giri (2016), Guo et al. (2017), Wang et al. (2018) and Pham et al. (2019) over the last two decades and have showed that a majority of the studies used optical and radar data groups while only a few studies used lidar, hyper-spectral data because of difficulty in accessing the data.

The optical satellite images, such as IKONOS, QuickBird, Landsat, SPOT, ALOS ASTER-2 Sentinel 2 and MODIS, are often used to understand the Difference Vegetation Index (DVI), Normalised Difference Vegetation Index (NDVI), Perpendicular Vegetation Index (PVI), Ratio Vegetation Index (RVI), etc. This is done using computational subtraction, division and rational transform groups and applying it while processing images from the red spectral band (R) and near-infrared band (NIR). The vegetative index describes the greenness of the leaves and the relative density and health of vegetation (Toderas et al., 1970; Rouse et al., 1974; Haas et al., 1975; Crippen, 1990; Green et al., 1998). Some impressive studies on mangroves, which use optical satellite data have been conducted. MacDonald (1999) used SPOT and Landsat images to study the rehabilitation of wetlands, including mangroves. Giri et al. (2007) used multi-time data from Landsat 2, 4, 5 and 7 to track mangrove variability in the Sundarbans in Bangladesh and India. Kamthonkiat et al. (2011) used ASTER data to assess the damage and subsequent rehabilitation of mangroves in southern Thailand. Kamal et al. (2016) used vegetation indexes from Landsat and ALOS AVNIR-2 satellite imagery in Moreton Bay of Australia and Karimunjawa island of Indonesia. Oostdijk et al. (2018) used a leaf area index (LAI) to monitor regional mangrove rehabilitation on the east coast of Florida. Chen et al. (2017) used NDVI from time-series Landsat 7/8 and Sentinel-1A imagery in Google Earth Engine cloud computing platform to analyse and create the mangrove forest map of China at $30 \mathrm{~m}$ spatial resolution, and it has an accuracy of more than 95\%. Long et al. (2011) used Landsat and ISODATA clustering techniques to map the spatial distribution and areal extent of mangrove forests in the Philippines. Luong et al. (2015) Nguyen et al. (2018) used SPOT for analysis of an impact of succession in mangrove association and changes in mangrove forests in Vietnam. Valderrame et al. (2018) used NDVI from SPOT5, Landsat 8 and Sentinel-2 for mapping mangrove forest in Mexico.

In radar images, the most commonly used data are $\mathrm{X}, \mathrm{C}$ and $\mathrm{L}$ bands from satellites such as RADARSAT-1 SAR, ENVISAT ASAR, ALOS-1/2 PALSAR-1/2 and Sentinel1. Since the early 90s, many studies have demonstrated that the backscatter data is correlated with the structure of the forest and used to build models to estimate forest biomass (Toan et al., 1992). Mougin et al. (1999) checked the correlation between the multi-frequency and multi-polarization from AIRSAR data in P-, L- and C bands with mangrove structural parameters such as height, diameter, density and basal area, which were collected from 12 locations at different periods from the mangrove forest in Guiana, France. They found that most forest parameters with radar data were potentially correlated (Mougin et al., 1999). Recent studies show that Cougo et al. (2015) used Radarsat 2 data to study the mangroves of southern Brazil, while Kovacs et al. (2013) used ALOS PALSAR for monitoring the biophysical parameter of the Avicennia germinans forest in the Mexican Pacific. Hong et al. (2015) applied band TerraSAR-X SAR data for the southern mangrove area of Florida, USA; Luong et al. (2019), Pham et al. (2019) and Pham, M.H et al. (2020) used ALOS-2 PLSAR-2 to estimate the 
mangrove biomass in Vietnam in their respective studies. Nesha et al. (2020) operated with ALOS-2 PALSAR-2 for the mangrove biomass in East Kalimantan, Indonesia. Lucas et al. (2020) combined multiple remote sensing data for the structural characterization of mangrove forests on the west coast of Peninsular Malaysia.

In general, the above studies that used remote sensing images for mangrove monitoring faced the following issues: (i) lack of reliable field data; (ii) some studies used optical satellite images to assess the area or/and the area change of mangrove forests only; (iii) some studies used radar satellite data while often focusing on analysing the structure of mangroves; (iv) some studies did not focus on both optical and radar satellite image data; (v) there was a lack of studies that monitored mangrove rehabilitation over a long period, especially in cases of forest restoration, where mangroves are completely absent or have been destroyed by herbicide in chemical warfare, as in our case study. Therefore, the existing databases are insufficient to evaluate mangrove rehabilitation (area, structure and speed) on an accurate scientific basis. Therefore, the objectives of this study are to overcome the limitations indicated above.

\section{Study area}

Geographic location: Can Gio is one of 24 districts of Ho Chi Minh City (HCMC) in Vietnam. The Can Gio mangrove forest lies entirely within the Can Gio district of HCMC. The area lies in the geographic co-ordinates between $10^{\circ} 22^{\prime} 14^{\prime \prime} \mathrm{N}-10^{\circ} 40^{\prime} 00^{\prime \prime} \mathrm{N}$ Latitude and $106^{\circ} 46^{\prime} 12^{\prime \prime}-107^{\circ} 00^{\prime} 59^{\prime \prime}$ E Longitude. It is about $65 \mathrm{~km}$ south of the HCMC centre and covers an area of over 75,000 ha (Tri et al., 2000; Tuan et al., 2002) (Fig. 1).

Topographically: Can Gio mangrove forest forms a basin with a minimum altitude range of $0 \mathrm{~m}-1.5 \mathrm{~m}$, in the northeastern sector of the forest, with downward inclines from the east, south and west (Tuan et al., 2002; Nam et al., 2014).

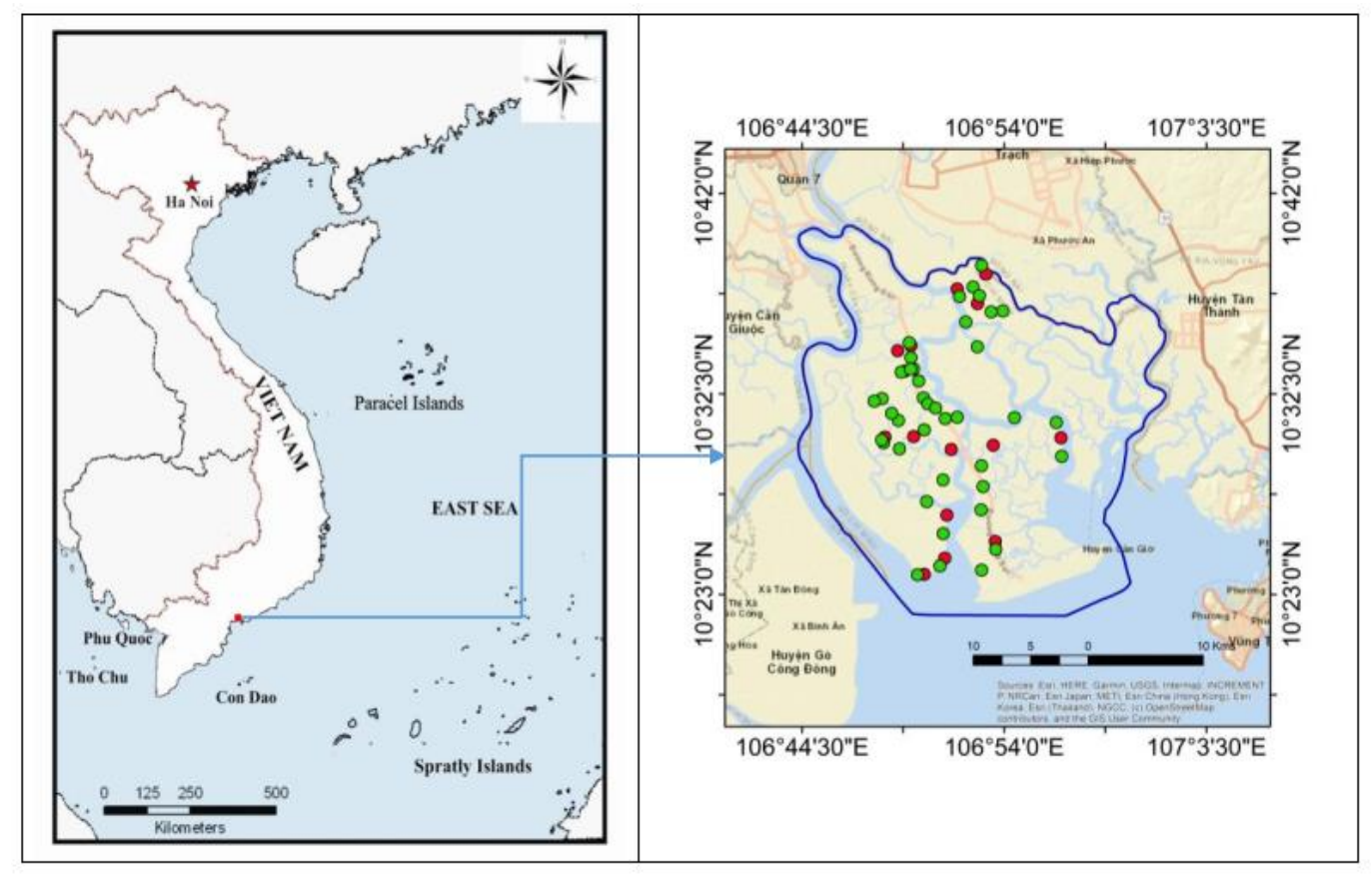

Figure 1. Location map of the study area, Can Gio Biosphere Reserve in HCMC and its boundary (blue polygon). Distribution of sample plots (training plot is green circle and validation plot is red circle) are also shown over the study area 
Soil: The Can Gio mangrove forest developed out of a comparatively recent brackish swamp, as the alluvium from the Sai Gon and Dong Nai rivers created. The soil types in Can Gio can be found four mains are saline soil, saline soil, with low alum content, saline soil, with high alum content and soft sandy soil, with mud deposits at the seashore (Tri et al., 2000; Tuan et al., 2002; Nam et al., 2014).

Climate: There are two seasons and the area is affected by equatorial monsoons; rainy season: from May to October and dry season: from November to April.

Temperature and humidity: The yearly average temperature is $25.8^{\circ} \mathrm{C}$. The daily average temperature amplitude is $5-7^{\circ} \mathrm{C}$. During the rainy season, humidity ranges from $79 \%-83 \%$, with a maximum of $83 \%$ in September. In the dry season, humidity ranges from $74 \%-77 \%$, with a minimum of $74 \%$ in April (Tuan et al., 2002; Nam et al., 2014).

Tidal regime: The Can Gio mangrove forest lies in a zone with a bi-diurnal tidal regime (i.e., two ebb and flow tides per day). Tidal amplitudes range from about $2 \mathrm{~m}$ at mean tide to $4 \mathrm{~m}$ during spring tides. However, the two daily high and low tides differ in height. Maximum tidal amplitudes, in the region of $4.0-4.2 \mathrm{~m}$ are the highest observed in the whole of Viet Nam (Tri et al., 2000; Tuan et al., 2002; Nam et al., 2014).

\section{Mangrove forests in the Can Gio district before the onset of chemical warfare (30 April 1975)}

According to Cuong (1964), before the war, the flora at Can Gio consisted of 34 species and was divided into two communities of salt-water (17 species) and brackishwater plants (17 species) (Cuong, 1964). The Can Gio mangrove forest covered an area of $40.000 \mathrm{ha}$; the canopy was dense with trees over $25 \mathrm{~m}$ tall and $25-50 \mathrm{~cm}$ wide (Cuong, 1964; Ross, 1974).

The Second Indochina War by the U.S. military in Vietnam, which used toxic chemicals, was the direst in human history. Between 1961 and 1971, the U.S. sprayed nearly 20 million gallons of Agent Orange and other herbicide across South Vietnam in an attempt to kill the vegetation that hid Vietnamese soldiers (Ross, 1974; Thomas, 1974).

According to Hong (2001), the mangrove ecosystem in Can Gio was completely destroyed (Hong, 2001). Besides that, chemical warfare has had a very serious and long-term impact on human health and the ecological environment (Schecter et al., 1995; Westing, 1983; Falk, 2015). The defoliant was sprayed on mangrove forests and other vegetation, which not only defoliated and killed plants but also destroyed the habitats of other organisms (Ross, 1974; Thomas, 1974; Nham Tuyet and Johansson, 2001; Koniuszewski, 2016).

Although trees remained standing after the spraying, they were dead. These dead trees remained in Can Gio for a short duration before the local people collected them and left the barren soil. The species Rhizophora apiculate and Rhizophora mucronata virtually disappeared. The trees that remained were small groups of Ceriops tagal and Excoecaria agallocha in a state of regeneration along the waterways; in tidal flooded areas, Avicenniaceae was present; on higher land, Phoenix paludosa, Acrostichum aureum, Gymnanthera nitida, Derris trifoliata, Azima sarmentosa, Pluchea indian and Clerodendrum inerme survived with a maximum height of only $2 \mathrm{~m}$, while in other areas, nothing was to be seen other than shrubs of Acanthus spp., Derris trifoliata, Finlaysonia obovate and Acrostichum aureum, etc. (Tuan et al., 2002). Besides that, severe coastal erosion was seen along rivers and canals due to a lack of protective mangrove tree belts (Nam, 1994). 


\section{Mangrove forests in the Can Gio district after the onset of chemical warfare (30 April 1975)}

On 7 August 1978, the Ho Chi Minh City (HCMC) People's Committee signed Decision No. 165/QD-UB, which set out to establish Duyen Hai Forest Plantation, belonging to the HCM Forest Department, with the main mission to provide a base to concentrate their mangrove forest ecosystem reforestation efforts. Following the suggestions by the Forest Department, Rhizophora apiculate was selected for the afforestation as this species is a native and fast-growing tree and would thus be able to restore forest cover at the fastest rate. It also has the highest commercial value (Tuan et al., 2002). After 1978, HCMC planted more than 20,000 ha of Rhizophora apiculata in the Can Gio District to restore the mangrove ecosystem and ensured that the mangrove forest would serve its dual functions of providing wood fuels and construction materials and protecting the environment (Tuan et al., 2002).

After 22 years of rehabilitation and development owing to the efforts of the Ho Chi Minh city committee and people, the Can Gio forest became the largest replanted mangrove area in Vietnam with a beautiful natural landscape and diverse flora and fauna. This led to its recognition as an International Mangrove Biosphere Reserve by MAB/UNESCO Committee on 21 January 2000 - the first biosphere reserve in Vietnam (Tuan et al., 2002).

\section{Data and methods}

\section{Satellite dataset}

In this study, we used four optical satellite imagery types - Landsat 1 (1972), Landsat 5 (1988, 1989, 1995, 2000, 2005), Landsat 7 (2002, 2010) and Landsat 8 (2015, 2020) - for the dynamic analysis of the mangrove cover in the study area. All the satellite images were carefully selected with not much difference in the observed time of the season and month, without any cloud cover and after ensuring they were of the best quality. The details on the Landsat satellite image series used in this study are shown in Table 1.

We also used the Advanced Land Observing Satellite-2 Synthetic Aperture Radar (ALOS-2 PALSAR-2), launched in 2014 by the Japan Aerospace Exploration Agency (JAXA), which operates in L-band radar and collects very high spatial resolution data. Two scenes from ALOS-2 PALSAR-2 data in 2020 with $10 \mathrm{~m}$ pixel resolution and version 2.1 were selected. The details on the ALOS-2 PALSAR-2 data used in this study are shown in Table 2 .

\section{Prep-processing image}

Processing of optical data: A series of processing was carried out before the image classification as-is: radiometric calibration as converted digital numbers (DN) value into spectral radiance and then converted into top-of-atmosphere reflectance (Chander et al., 2009; Potapov et al., 2020) and removed the gap on the Landsat 7 image by "Landsat_gapfill.sav" tool. Geometric correction; Image to map rectification; Image to Image registration. Mosaic and cut images were used according to the boundaries of the study area to reduce the size before classifying. For landcover change analysis, we used the post-classification comparison method based on supervised classification. In this study, we have chosen the NDVI, because it is one of the physiological parameters that 
correlate with the photosynthetic activity of vegetation. It is a good index extracted from optical remote sensing data and is widely used (DeFries et al., 1995; Xie et al., 2008; Luong et al., 2016; Thuy et al., 2020). The vegetative index that was selected for the landcover classification was the Normalised Difference Vegetation Index (NDVI) and was calculated as a ratio between the RED band and NIR band values using the following formula:

$$
\mathrm{NDVI}=\frac{\mathrm{NIR}-\mathrm{RED}}{\mathrm{NIR}+\mathrm{RED}}
$$

In Equation 1: RED is the red band and NIR is the near-infrared band.

Table 1. Landsat data used in this research

\begin{tabular}{c|c|c|c|c|c}
\hline No. & Type & Scene ID & $\begin{array}{c}\text { Part/ } \\
\text { row }\end{array}$ & $\begin{array}{c}\text { Observation } \\
\text { time }\end{array}$ & $\begin{array}{c}\text { Band used } \\
\text { (Pixel resolution) }\end{array}$ \\
\hline 1 & Landsat 1 & p134r53_1m19721215 & $134 / 53$ & $12 / 15 / 1972$ & Band 3, 4 (57 m) \\
2 & Landsat 5 & LT05_L1TP_124053_19890125_20170205_01_T1 & $124 / 53$ & $1 / 25 / 1989$ & Band 3, 4 (30 m) \\
3 & Landsat 5 & LT05_L1TP_125053_19880114_20170210_01_T1 & $125 / 53$ & $1 / 14 / 1988$ & Band 3, 4 (30 m) \\
4 & Landsat 5 & LT05_L1TP_124053_19950110_20170110_01_T1 & $124 / 53$ & $10 / 1 / 1995$ & Band 3, 4 (30 m) \\
5 & Landsat 5 & LT05_L1TP_125053_19950202_20170110_01_T1 & $125 / 53$ & $2 / 2 / 1995$ & Band 3, 4 (30 m) \\
6 & Landsat 5 & LT05_L1TP_124053_20010315_20161212_01_T1 & $124 / 53$ & $3 / 15 / 2001$ & Band 3, 4 (30 m) \\
7 & Landsat 5 & LT05_L1TP_124053_20050105_20161129_01_T1 & $124 / 53$ & $1 / 5 / 2005$ & Band 3, 4 (30 m) \\
8 & Landsat 5 & LT05_L1TP_125053_20050317_20161126_01_T1 & $125 / 53$ & $3 / 17 / 2005$ & Band 3, 4 (30 m) \\
9 & Landsat 7 & LE07_L1TP_124053_20020310_20170131_01_T1 & $124 / 53$ & $3 / 10 / 2002$ & Band 3, 4 (30 m) \\
10 & Landsat 7 & LE07_L1TP_124053_20100127_20161215_01_T1 & $124 / 53$ & $1 / 27 / 2010$ & Band 3, 4 (30 m) \\
11 & Landsat 8 & LC08_L1TP_124053_20150218_20170412_01_T1 & $124 / 53$ & $2 / 18 / 2015$ & Band 4, 5 (30 m), Band 8 (15 m) \\
12 & Landsat 8 & LC08_L1TP_125053_20150209_20180523_01_T1 & $125 / 53$ & $2 / 9 / 2015$ & Band 4, 5 (30 m), Band 8 (15 m) \\
13 & Landsat 8 & LC08_L1TP_124053_20200115_20200127_01_T1 & $124 / 53$ & $1 / 15 / 2020$ & Band 4, 5 (30 m), Band 8 (15 m) \\
14 & Landsat 8 & LC08_L1TP_125053_20200207_20200211_01_T1 & $125 / 53$ & $2 / 7 / 2020$ & Band 4, 5 (30 m), Band 8 (15 m) \\
\hline
\end{tabular}

Table 2. ALOS-2 PALSAR-2 data used in this research

\begin{tabular}{c|c|c|c|c}
\hline No. & Scene ID & $\begin{array}{c}\text { Observation } \\
\text { time }\end{array}$ & $\begin{array}{c}\text { Polarization } \\
\text { (pixel resolution) }\end{array}$ & Observation angle \\
\hline 1 & ALOS2314580190-200320 & $2020-03-20$ & HH, HV $(10 \mathrm{~m})$ & Off-nadia[deg]: 36.2 \\
2 & ALOS2314580200-200320 & $2020-03-20$ & HH, HV $(10 \mathrm{~m})$ & Off-nadia[deg]: 36.2 \\
\hline
\end{tabular}

Processing of radar data: In this study, we used satellite images from ALOS-2 PALSAR-2. The digital number (DN) values of the ALOS-2 PALSAR-2 images in both the $\mathrm{HH}$ and $\mathrm{HV}$ polarizations were calibrated by calculating the backscattering intensity using Equation 2:

$$
\sigma^{\circ}=10 * \log _{10}\left(\mathrm{DN}^{2}\right)+F C
$$

In Equation 2: $\sigma^{\circ}$ is the sigma naught backscattering intensity and $C F$ is the calibration factor, which is currently set as -83 (JAXA, 2014).

In this study, we also used eight texture values from the ALOS-2 PALSAR-2 image including, Contrast, Correlation, Dissimilarity, Entropy, Homogeneity, Mean, Second Moment and Variance (Haralick et al., 1973; Anys et al., 1994; Luong et al., 2016). 


\section{Field survey and structure calculations}

We carried out a field measurements campaign during July 2020, and each sample plot had a size of $500 \mathrm{~m}^{2}(20 \times 25 \mathrm{~m})$. Geographical coordinates (latitudes and longitudes) were identified at the centre of each plot using a GPS instrument. All trees larger than $5 \mathrm{~cm}$ in diameter (at 1.3 positions) were measured. The measuring instruments used were Criterion RD1000 Laser (Diameter at breast height- $1.3 \mathrm{~m}$ position of tree/ $\mathrm{D}_{1.3 \mathrm{~m}}$ ) and Trupulse 360B Laser (Height from stump to the top of the crown $/ \mathrm{H}$ ). Other instruments such as tape rope and digital camera were also applied. The authors used the plus average method for parameters measured (diameter, height and density) in each sample plot and convert to per hectare Vo Van Hong et al., 2006).

\section{Field above ground biomass (AGB) and woody volume (V) estimation}

We used allometric Equations 3-11 for calculating the above-ground biomass (AGB) according to previous studies by (Ong et al., 2004; Fromard et al., 1998; Clough and Scott, 1998; Binh., 2007; Hoan et al., 2009; Komiyama et al., 2005; IPCC, 2003) in Table 3.

Table 3. Allometric equations used for AGB mangroves species in the study area

\begin{tabular}{|c|c|c|c|}
\hline Species & Allometric equations & References & Equation \\
\hline Bruguiera gymnorrhiza & $\mathrm{AGB}=0.186 * \mathrm{D}^{2.31}\left(\mathrm{R}^{2}=0.99\right)$ & Clough and Scott (1989) & (Eq.3) \\
\hline Bruguiera parviflora & AGB $=0.168 * D^{2.42}\left(R^{2}=0.99\right)$ & Clough and Scott (1989) & (Eq.4) \\
\hline Xylocarpus granatum & AGB $=0.0823 * D^{2.59}\left(R^{2}=0.99\right)$ & Clough and Scott (1989) & (Eq.5) \\
\hline Avicennia germinans & $\mathrm{AGB}=0.140 * \mathrm{D}^{2.40}\left(\mathrm{R}^{2}=0.97\right)$ & Fromard et al. (1998) & (Eq.6) \\
\hline Rhizophora appiculata & $\mathrm{AGB}=0.235 * \mathrm{D}^{2.42}\left(\mathrm{R}^{2}=0.98\right)$ & Ong et al. (2004) & (Eq.7) \\
\hline Sonneratia caseolaris & $\mathrm{AGB}=0.199 * p^{0.90} * \mathrm{D}^{2.22}\left(\mathrm{R}^{2}=0.99\right)$ & Komiyama et al. (2005) & (Eq.8) \\
\hline Ceriops decandra & $\mathrm{AGB}=0.208 * \mathrm{D}^{2.36}\left(\mathrm{R}^{2}=0.96\right)$ & Cao Huy Binh (2007) & (Eq.9) \\
\hline Lumnitzera racemosa & $\mathrm{AGB}=0.74 * \mathrm{D}^{2.92}\left(\mathrm{R}^{2}=0.99\right)$ & Hoan et al. (2009) & (Eq.10) \\
\hline Common equation & $\mathrm{AGB}=0.25 * 0 * \mathrm{D}^{-592}\left(\mathrm{R}^{2}=0.98\right)$ & Komiyama et al. (2005) & (Eq.11) \\
\hline
\end{tabular}

In allometric Equations 3-11: AGB is the aboveground biomass of a tree in kilograms $(\mathrm{kg}) ; \mathrm{D}$ is the diameter at breast height $(1.3 \mathrm{~m})$ in centimeters $(\mathrm{cm}) ; \rho$ is the wood density (tons dry matter $/ \mathrm{m}^{3}$ fresh volume) (IPCC, 2003)

The woody volume (V) of each tree was calculated by using Equation 12 which uses the basal area of a tree at breast height $(\mathrm{G})$ in squared meters $\left(\mathrm{m}^{2}\right)$, total tree height $(\mathrm{H})$ in meters $(\mathrm{m})$ and the conversion factor $(\mathrm{F})$.

$$
\mathrm{V}=\mathrm{G} * \mathrm{H} * \mathrm{~F}
$$

In Equation 12: $\mathrm{V}$ is the woody volume $\left(\mathrm{m}^{3}\right) ; \mathrm{G}$ is the basal area of tree at breast height $1.3 \mathrm{~m}$ in squared meters $\left(\mathrm{m}^{2}\right) ; \mathrm{H}$ is the total tree height $(\mathrm{H})$ in meters $(\mathrm{m})$, and $\mathrm{F}$ is the conversion factor $(\mathrm{F})$.

A total of 60 sample plots were used in this study. We have randomly selected 42 sample plots for training data and 18 sample plots for validation data. The summary of mangrove inventory parameters in the study area is described in Table 4. The location distribution of the sample plots in the study area is shown in Figure 1. 
Table 4. Parameters of the mangrove structure from sample plots in the study area

\begin{tabular}{c|c|c|c|c|c}
\hline No. & Parameter & Minimum & Maximum & Mean & Standard deviation \\
\hline 1 & Diameter $(\mathrm{cm})$ & 8.30 & 24.40 & 17.11 & 3.29 \\
2 & Height (m) & 7.89 & 18.70 & 14.44 & 2.11 \\
3 & Density (tree/ha) & 280 & 1430 & 680 & 243 \\
4 & Biomass (ton) & 36.22 & 398 & 153.44 & 243.11 \\
5 & Woody (m $\left.\mathrm{m}^{3}\right)$ & 13.45 & 263.86 & 109.97 & 67.34 \\
\hline
\end{tabular}

\section{Land cover classification}

In this study, we have applied Circular No. 33/2018/TT-BNNPTNT (MARD, 2018) from the Ministry of Agriculture and Development of Vietnam. It has adopted the classification criteria of the UNESCO (1973) and Thai Van Trung (1998) for the division of the landcover at the Can Gio Mangrove Biosphere Reserve into two main classes and six sub-classes such as Forest class (Class 1. Very rich forest; Class 2. Rich forest; Class 3. Medium forest; Class 4. Poor forest) and sub-classes (Class 5. Other land and Class 6. Water body) (Luong et al., 2019). We have also temporarily divided the mangrove biomass level in this study area into four classes (Table 5).

Table 5. The criterion for the classification of woody volumes and biomass forest classes

\begin{tabular}{|c|c|c|c|c|}
\hline \multirow[b]{2}{*}{ No. } & \multirow[b]{2}{*}{ Main-class } & \multirow[b]{2}{*}{ Sub-class } & \multicolumn{2}{|c|}{ Forest classification criterion } \\
\hline & & & $\begin{array}{l}\text { Woody volumes } \\
\left(\mathbf{m}^{3} / \mathbf{h a}\right)\end{array}$ & biomass forests (ton/ha) \\
\hline 1 & \multirow{4}{*}{ Forest } & Very rich forest & $>300$ & $>300$ \\
\hline 2 & & Rich forest & $200-300$ & $200-300$ \\
\hline 3 & & Medium forest & $100-200$ & $100-200$ \\
\hline 4 & & Poor forest & $0-100$ & $0-100$ \\
\hline 5 & \multirow{2}{*}{ Non-forest } & Other land & 0 & 0 \\
\hline 6 & & Water body & 0 & 0 \\
\hline
\end{tabular}

Assessing the classification accuracy: A confusion matrix or error matrix is usually used as the quantitative method of characterising image classification accuracy. It is a table that will describe correspondence between the object classification results from satellite images and the ground truths with GPS points recorded. The Kappa test statistic assesses interclassifier agreement and is applied in assessing the classification accuracy of two classifiers, a neural network and a decision tree model on the same data set, therefore, the higher the kappa coefficient, the more accurate the classification of forest vegetation from satellite images (Fitzgerald et al., 1994). At a minimum, a Kappa Coefficient of Agreement should be attached to any resultant classification of satellite imagery (Jager et al., 2000).

\section{Results}

\section{Land cover map and area distribution in the Can Gio Biosphere Reserve} 1972

The land cover map based on the supervised classification of Landsat 1 in 1972 is given in Figure 2 and the results of the statistical analysis of the landcover are shown in Table 6. 


$$
\text { - } 3906 \text { - }
$$

At this time (1972), the very rich forests, the rich forests and the medium forests did not appear in this area, only poor forests with an area of $7,158.15$ ha $(9.54 \%)$ were spotted.

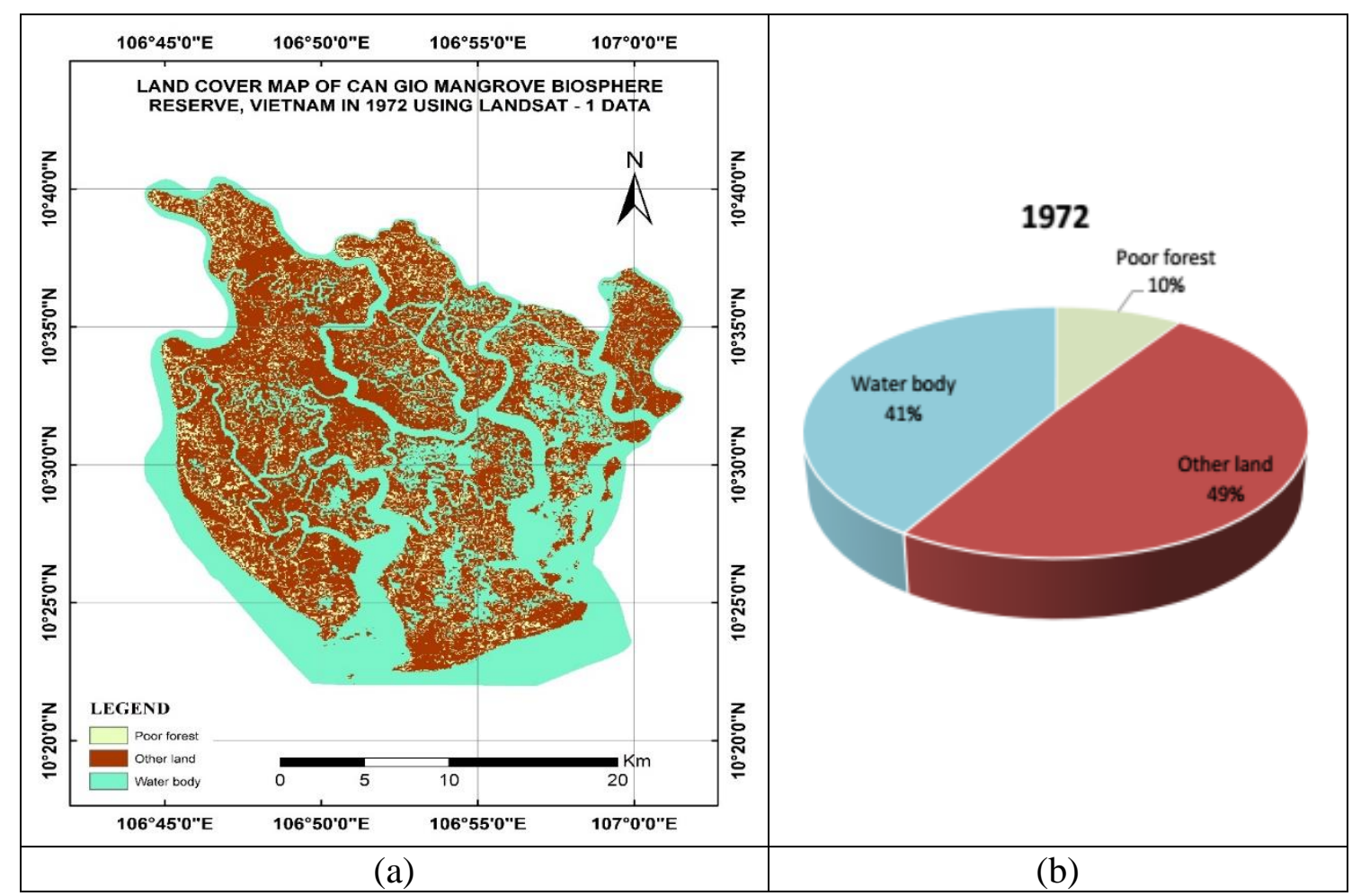

Figure 2. (a) Land cover map and (b) area distribution in the Can Gio Biosphere Reserve in 1972

Table 6. Statistics on the land cover area in the Can Gio Biosphere Reserve in 1972

\begin{tabular}{c|c|c|c|c}
\hline \multirow{2}{*}{ No. } & \multirow{2}{*}{ Main-class } & Sub-class & \multicolumn{2}{|c}{ Area } \\
\cline { 3 - 4 } & & Very rich forest & 0 & 0 \\
2 & & Rich forest & 0 \\
3 & \multirow{3}{*}{ Forest } & Medium forest & 0 & 0 \\
4 & & Poor forest & 7158.15 & 9.54 \\
& & Sub-total & $\mathbf{7 1 5 8 . 1 5}$ & $\mathbf{9 . 5 4}$ \\
\hline 5 & & Other land & 36851.22 & 49.10 \\
6 & \multirow{3}{*}{ Non-forest } & Water body & 31039.39 & 41.36 \\
& & Sub-total & $\mathbf{6 7 8 9 0 . 6 1}$ & $\mathbf{9 0 . 4 6}$ \\
& & Total & $\mathbf{7 5 0 4 8 . 7 6}$ & $\mathbf{1 0 0 . 0 0}$ \\
\hline
\end{tabular}

1988

The land cover map based on the supervised classification of Landsat 5 in 1988 had given in Figure 3 and the results of the statistical analysis of the landcover are shown in Table 7.

The statistical results from the classified land cover map in 1988 using Landsat 5 show that the medium forest area is 6695.46 ha $(8.92 \%)$, the poor forest area is 


$$
\text { - } 3907 \text { - }
$$

19170.00 ha $(25.54 \%)$, the other land area is 19480.14 ha $(25.96 \%)$, and the water body area is 29703.16 ha $(39.58 \%)$.

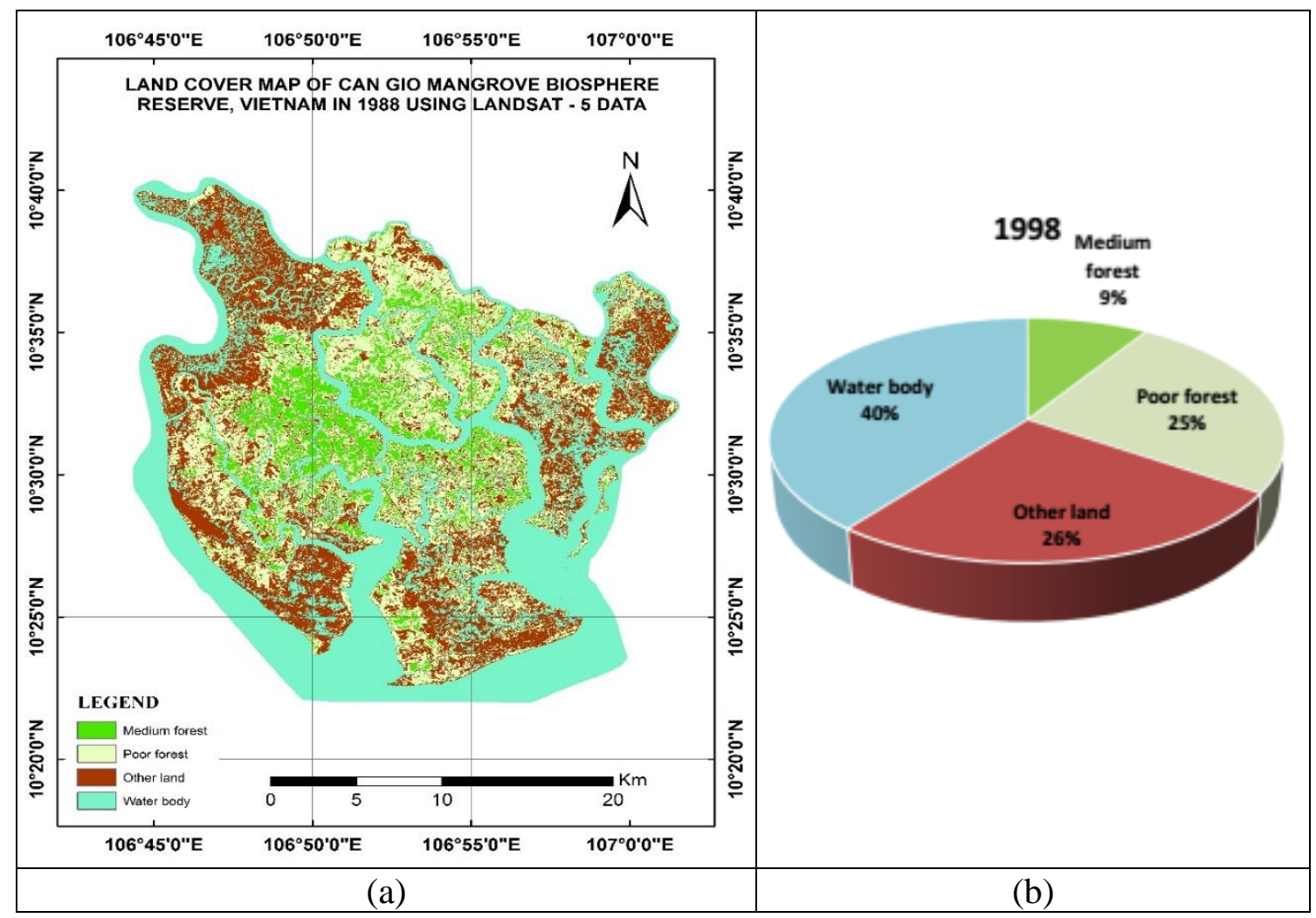

Figure 3. (a) Land cover map and (b) area distribution in the Can Gio Biosphere Reserve in 1988

Table 7. Statistics on the land cover area in the Can Gio Biosphere Reserve in 1988

\begin{tabular}{c|c|c|c|c}
\hline \multirow{2}{*}{ No. } & \multirow{2}{*}{ Main-class } & Sub-class & \multicolumn{2}{|c}{ Area } \\
\cline { 3 - 4 } & & ha & \% \\
\hline 1 & \multirow{3}{*}{ Forest } & Very rich forest & 0 & 0 \\
3 & & Rich forest & 6695.46 & 8.92 \\
4 & & Medium forest & 19170.00 & 25.54 \\
& & Poor forest & $\mathbf{2 5 8 6 5 . 4 6}$ & $\mathbf{3 4 . 4 6}$ \\
\hline 5 & & Sub-total & 19480.14 & 25.96 \\
6 & \multirow{3}{*}{ Non-forest } & Other land & 29703.16 & 39.58 \\
& & Water body & $\mathbf{4 9 1 8 3 . 3 0}$ & $\mathbf{6 5 . 5 4}$ \\
& & Sub-total & $\mathbf{7 5 0 4 8 . 7 6}$ & $\mathbf{1 0 0}$ \\
\hline
\end{tabular}

The land cover map based on the supervised classification of Landsat 5 in 1995 is given in Figure 4 and the results of statistical analysis of the landcover are shown in Table 8 .

The statistical results from the classified land cover map in 1995 by using Landsat 5 show that the rich forest area is 8995.05 ha $(11.99 \%)$, the medium forest area is 


$$
\text { - } 3908 \text { - }
$$

13205.43 ha $(17.60 \%)$, the poor forest area is 12578.85 ha $(16.45 \%)$, the other land area is 12345.67 ha $(16.76 \%)$, the water body area is 27923.76 ha $(37.21 \%)$.

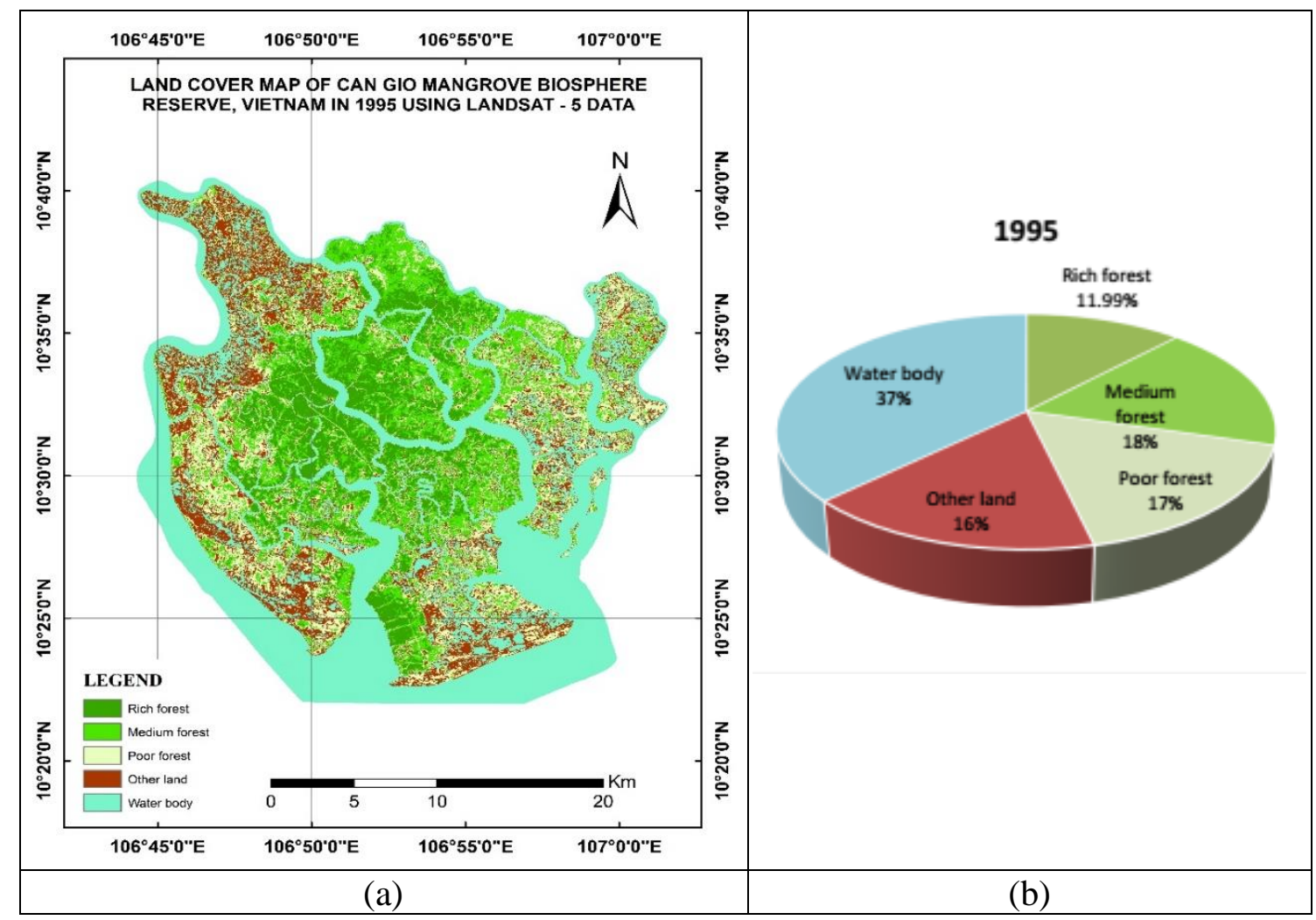

Figure 4. (a) Land cover map and (b) area distribution in the Can Gio Biosphere Reserve in 1995

Table 8. Statistics on the land cover area in the Can Gio Biosphere Reserve in 1995

\begin{tabular}{c|c|c|c|c}
\hline \multirow{2}{*}{ No. } & \multirow{2}{*}{ Main-class } & Sub-class & \multicolumn{2}{|c}{ Area } \\
\cline { 3 - 4 } & & ha & \% \\
\hline 1 & & Very rich forest & 0.00 & 0.00 \\
3 & \multirow{3}{*}{ Forest } & Rich forest & 8995.05 & 11.99 \\
4 & & Medium forest & 13205.43 & 17.60 \\
& & Poor forest & 12578.85 & 16.76 \\
\hline 5 & & Sub-total & $\mathbf{3 4 7 7 9 . 3 3}$ & $\mathbf{4 6 . 3 4}$ \\
\hline 6 & \multirow{3}{*}{ Non-forest } & Other land & 12345.67 & 16.45 \\
& & Water body & 27923.76 & 37.21 \\
& & Sub-total & $\mathbf{4 0 2 6 9 . 4 3}$ & $\mathbf{5 3 . 6 6}$ \\
& & Total & $\mathbf{7 5 0 4 8 . 7 6}$ & $\mathbf{1 0 0 . 0 0}$ \\
\hline
\end{tabular}

The land cover map based on the supervised classification of Landsat 5 in 2000 is given in Figure 5 and the results of statistical analysis of the landcover are shown in Table 9.

The statistical results from the classified land cover map in 2000 using Landsat 5 indicate that the very rich area is $1625.58 \mathrm{ha}(2.17 \%)$, the rich forest area is $15122.61 \mathrm{ha}$ $(20.15 \%)$, the medium forest area is 11724.88 ha $(15.62 \%)$, the poor forest area is 
10375.16 ha (13.82\%), the other land area is 8530.93 ha $(11.37 \%)$, and the water body area is 27669.60 ha $(36.87 \%)$.

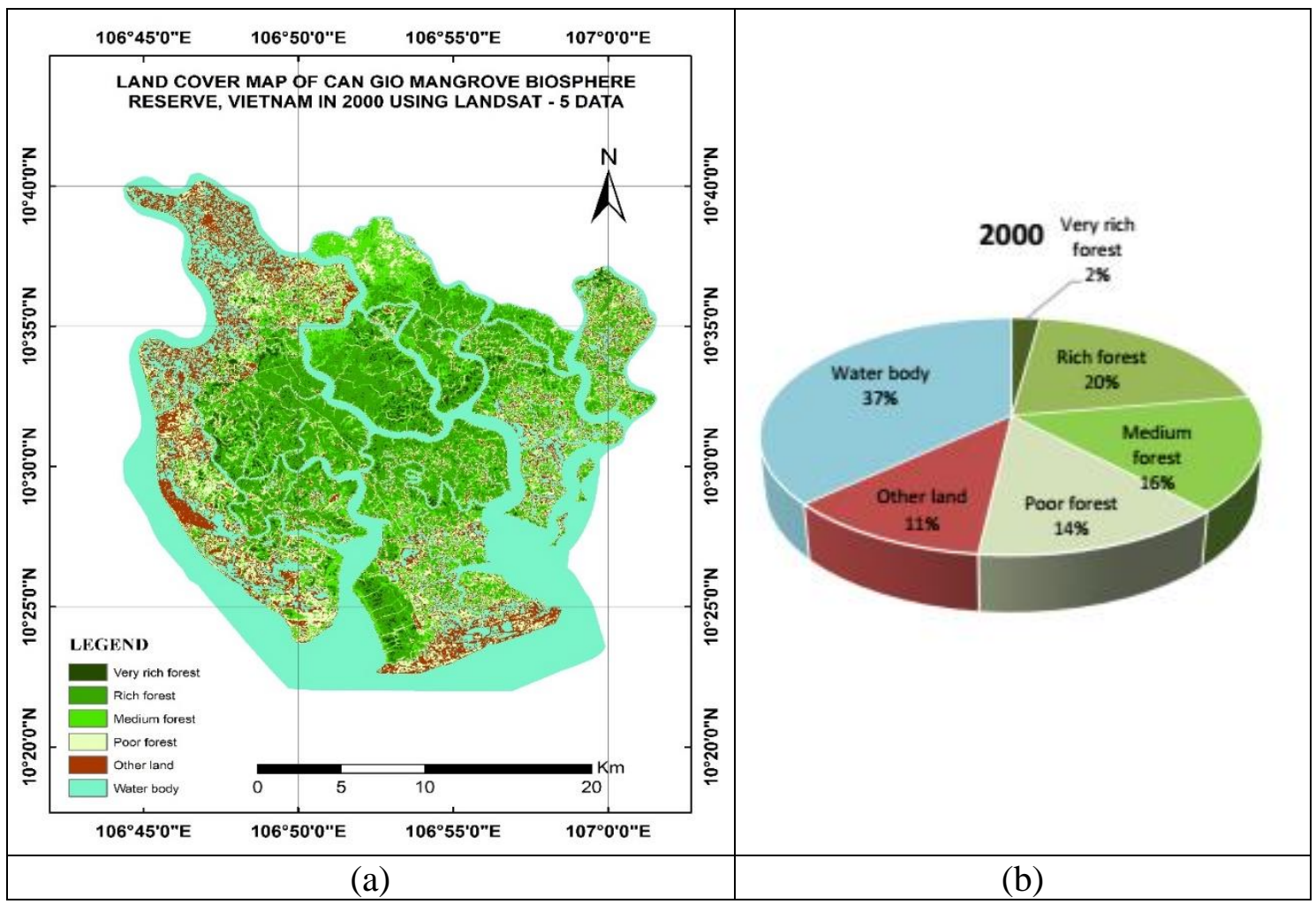

Figure 5. (a) Land cover map and (b) area distribution in the Can Gio Biosphere Reserve in 2000

Table 9. Statistics on the land cover area in the Can Gio Biosphere Reserve in 2000

\begin{tabular}{c|c|c|c|c}
\hline \multirow{2}{*}{ No. } & \multirow{2}{*}{ Main-class } & Sub-class & \multicolumn{2}{|c}{ Area } \\
\cline { 3 - 4 } & & Very rich forest & 1625.58 & $\%$ \\
2 & & Rich forest & 15122.61 & 2.17 \\
3 & \multirow{3}{*}{ Forest } & Medium forest & 11724.88 & 15.62 \\
4 & & Poor forest & 10375.16 & 13.82 \\
& & Sub-total & $\mathbf{3 8 8 4 8 . 2 3}$ & $\mathbf{5 1 . 7 6}$ \\
\hline 5 & & Other land & 8530.93 & 11.37 \\
6 & \multirow{3}{*}{ Non-forest } & Water body & 27669.60 & 36.87 \\
& & Sub-total & $\mathbf{3 6 2 0 0 . 5 3}$ & $\mathbf{4 8 . 2 4}$ \\
& & Total & $\mathbf{7 5 0 4 8 . 7 6}$ & $\mathbf{1 0 0 . 0 0}$ \\
\hline
\end{tabular}

The land cover map based on the supervised classification of Landsat 5 in 2005 is given in Figure 6 and the results of the statistical analysis of the landcover are shown in Table 10.

The statistical results from the classified land cover map in 2005 using Landsat 5 indicate that the very rich forest area is 4892.91 ha $(6.52 \%)$, the rich forest area is 15382.35 ha $(20.50 \%)$, the medium forest area is 11888.77 ha $(15.84 \%)$, the poor forest 


$$
\text { - } 3910 \text { - }
$$

area is 8567.19 ha $(11.42 \%)$, the other land area is 6850.80 ha $(9.13 \%)$, the water body area is 27466.74 ha $(36.60 \%)$.

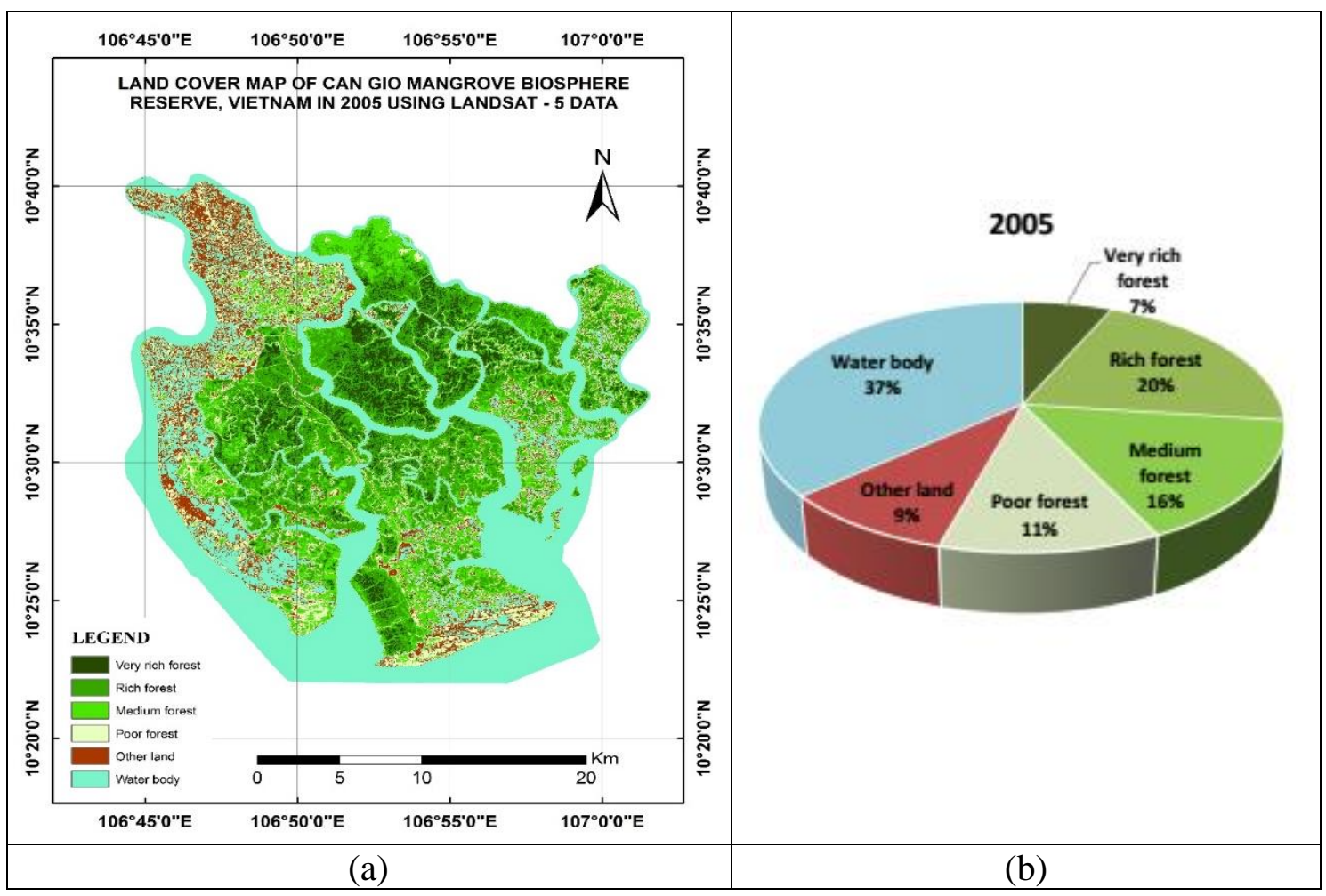

Figure 6. (a) Land cover map and (b) area distribution in the Can Gio Biosphere Reserve in 2005

Table 10. Statistics on the land cover area in the Can Gio Biosphere Reserve in 2005

\begin{tabular}{c|c|c|c|c}
\hline \multirow{2}{*}{ No. } & \multirow{2}{*}{ Main-class } & Sub-class & \multicolumn{2}{|c}{ Area } \\
\cline { 3 - 4 } & & ha & 4892.91 & \% \\
\hline 1 & & Rich forest & 15382.35 & 20.50 \\
2 & \multirow{3}{*}{ Forest } & Medium forest & 11888.77 & 15.84 \\
3 & & Poor forest & 8567.19 & 11.42 \\
4 & & Sub-total & $\mathbf{4 0 7 3 1 . 2 2}$ & $\mathbf{5 4 . 2 7}$ \\
\hline 5 & & Other land & 6850.80 & 9.13 \\
6 & \multirow{3}{*}{ Non-forest } & Water body & 27466.74 & 36.60 \\
& & Sub-total & $\mathbf{3 4 3 1 7 . 5 4}$ & $\mathbf{4 5 . 7 3}$ \\
& & Total & $\mathbf{7 5 0 4 8 . 7 6}$ & $\mathbf{1 0 0 . 0 0}$ \\
\hline
\end{tabular}

The land cover map based on the supervised classification of Landsat 7 in 2010 is given in Figure 7 and the results of the statistical analysis of the landcover are shown in Table 11.

The statistical results from the classified land cover map in 2010 from Landsat 7 indicate that the very rich forest area is 9433.27 ha $(12.57 \%)$, the rich forest area is 15121.80 ha $(20.15 \%)$, the medium forest area is 11152.53 ha $(14.86 \%)$, the poor forest 


$$
\text { - } 3911 \text { - }
$$

area is 7016.67 ha $(14.86 \%)$, the other land area is 5.312 .70 ha $(7.08 \%)$, the water body area is 27.011 .79 ha $(35.99 \%)$.

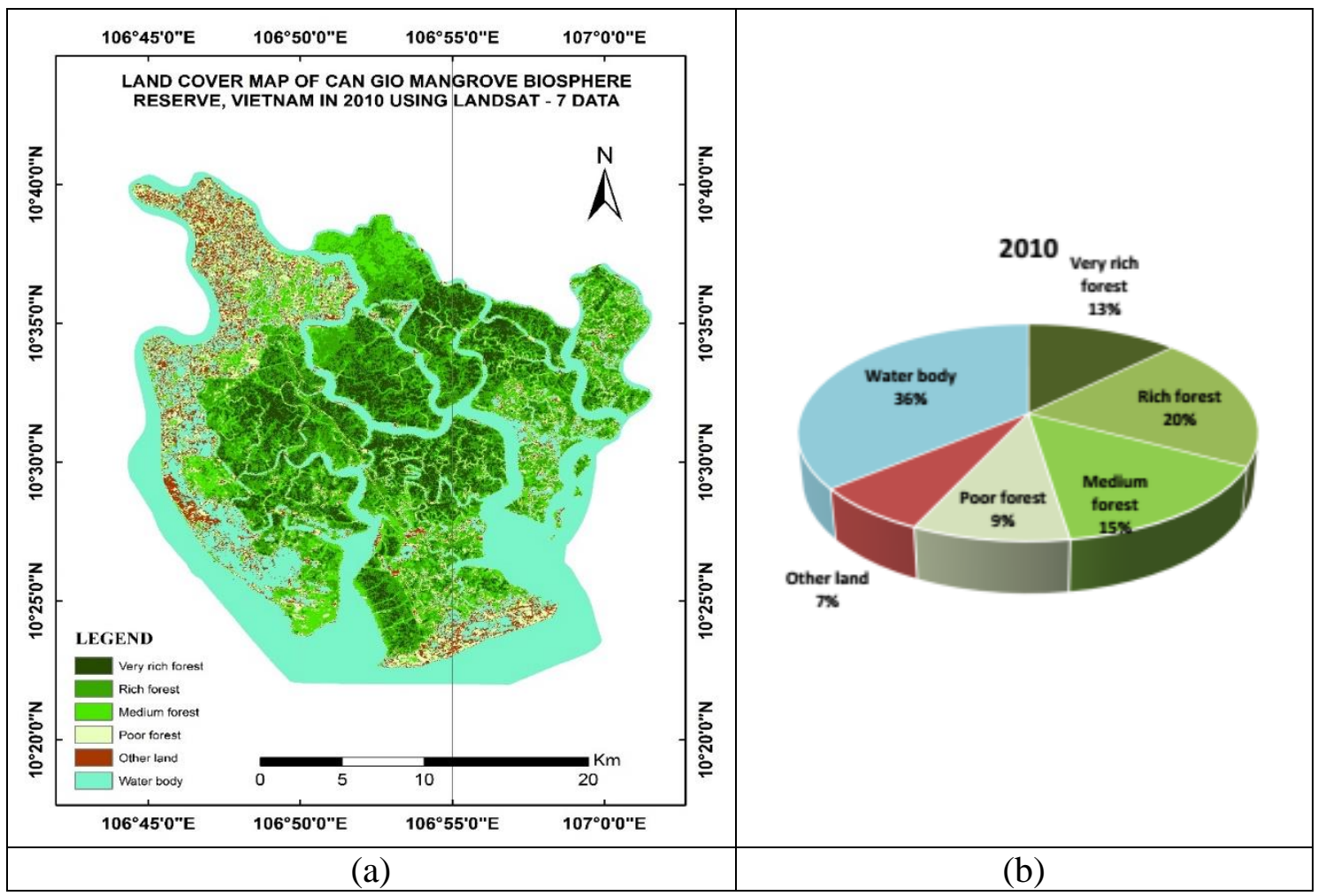

Figure 7. (a) Land cover map and (b) area distribution in the Can Gio Biosphere Reserve in 2010

Table 11. Statistics on the land cover area in the Can Gio Biosphere Reserve in 2010

\begin{tabular}{c|c|c|c|c}
\hline \multirow{2}{*}{ No. } & Main-class & Sub-class & \multicolumn{2}{|c}{ Area } \\
\cline { 3 - 5 } & & & 9433.27 & 12.57 \\
2 & \multirow{3}{*}{ Forest } & Very rich forest & 15121.80 & 20.15 \\
3 & & Rich forest & 11152.53 & 14.86 \\
4 & & Medium forest & 7016.67 & 9.35 \\
& & Poor forest & $\mathbf{4 2 7 2 4 . 2 7}$ & $\mathbf{5 6 . 9 3}$ \\
\hline 5 & \multirow{3}{*}{5} & Sub-total & 5.312 .70 & 7.08 \\
& & Other land & 27.011 .79 & 35.99 \\
& & Water body & $\mathbf{3 2 3 2 4 . 4 9}$ & $\mathbf{4 3 . 0 7}$ \\
\hline
\end{tabular}

2015

The land cover map based on the supervised classification of Landsat 8 in 2015 is given in Figure 8 and the results of statistical analysis of the landcover are shown in Table 12.

The statistical results from the classified land cover map in 2015 from Landsat 8 indicate that the very rich forest area is 10161.18 ha $(13.54 \%)$, the rich forest area is 


$$
\text { - } 3912 \text { - }
$$

18728.36 ha $(24.96 \%)$, the medium forest area is 9355.57 ha $(12.47 \%)$, the poor forest area is 6717.47 ha $(8.95 \%)$, the other land area is 4474.71 ha $(5.96 \%)$, the water body area is 25611.48 ha $(34.13 \%)$.

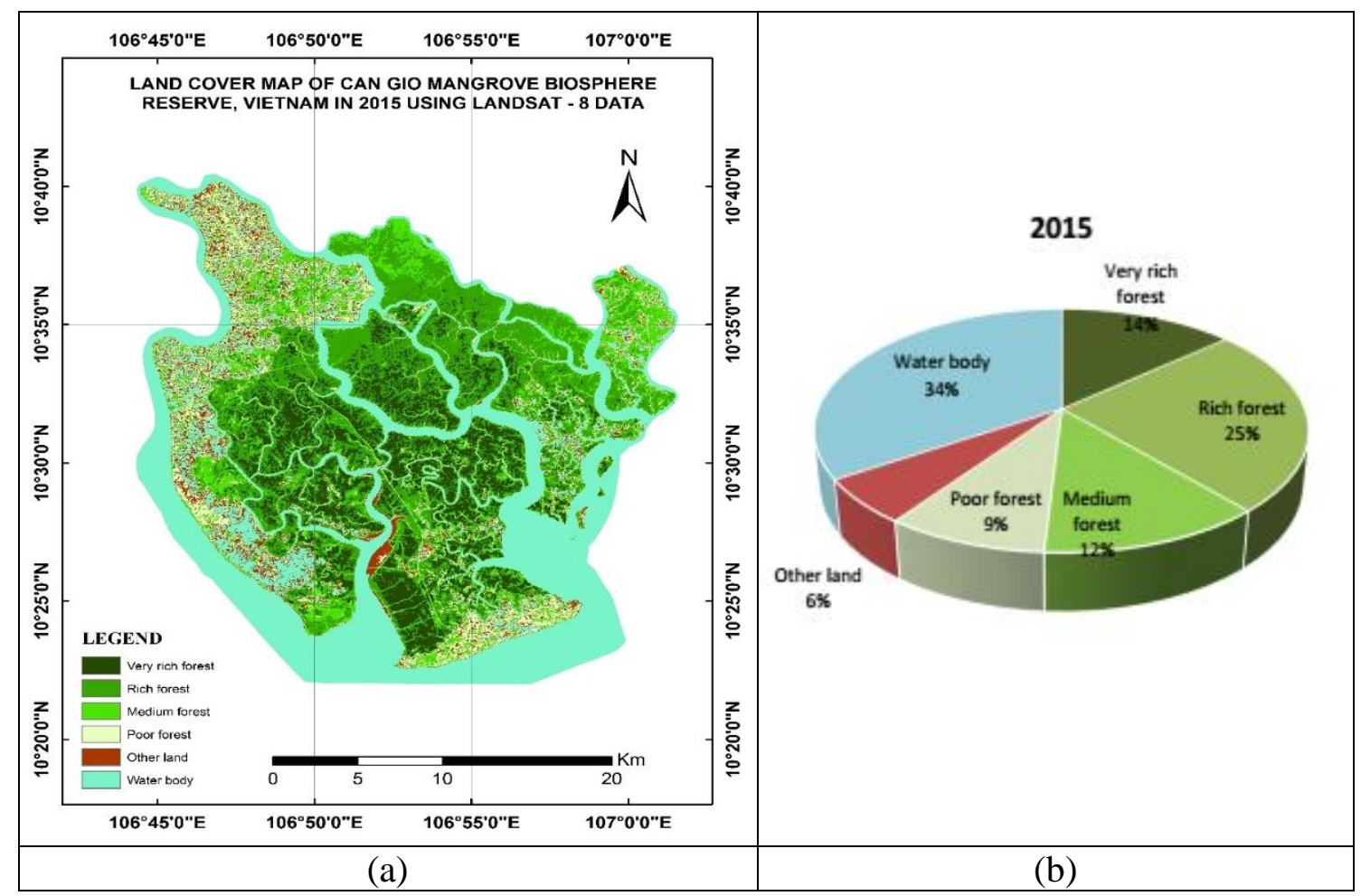

Figure 8. (a) Land cover map and (b) area distribution in the Can Gio Biosphere Reserve in 2015

Table 12. Statistics on the land cover area in the Can Gio Biosphere Reserve in 2015

\begin{tabular}{|c|c|c|c|c|}
\hline \multirow{2}{*}{ No. } & \multirow{2}{*}{ Main-class } & \multirow{2}{*}{ Sub-class } & \multicolumn{2}{|c|}{ Area } \\
\hline & & & ha & $\%$ \\
\hline 1 & \multirow{5}{*}{ Forest } & Very rich forest & 10161.18 & 13.54 \\
\hline 2 & & Rich forest & 18728.36 & 24.96 \\
\hline 3 & & Medium forest & 9355.57 & 12.47 \\
\hline \multirow[t]{2}{*}{4} & & Poor forest & 6717.47 & 8.95 \\
\hline & & Sub-total & 44962.57 & 59.91 \\
\hline 5 & \multirow{4}{*}{ Non-forest } & Other land & 4474.71 & 5.96 \\
\hline \multirow[t]{3}{*}{6} & & Water body & 25611.48 & 34.13 \\
\hline & & Sub-total & 30086.19 & 40.09 \\
\hline & & Total & 75048.76 & 100.00 \\
\hline
\end{tabular}

2020

The land cover map based on the supervised classification of Landsat 8 in 2020 is given in Figure 9 and the results of statistical analysis of the landcover are shown in Table 13.

The statistical results from the classified land cover map in 2020 from Landsat 8 show that the very rich forest area is 11994.93 ha $(15.98 \%)$, the rich forest area is 


$$
\text { - } 3913 \text { - }
$$

21659.20 ha $(28.86 \%)$, the medium forest area is 8572.88 ha $(11.42 \%)$, the poor forest area is 5578.09 ha $(7.43 \%)$, the other land area is 2198.27 ha $(2.93 \%)$, the water body area is 25045.39 ha (33.37\%) (Table 14). The classification accuracy assessment is based on the confusion matrix. The overall accuracy is $92.76 \%$ and the average accuracy of $85.47 \%$. Kappa statistics $\left(\mathrm{K}^{\wedge}\right)$ is $89.99 \%$.

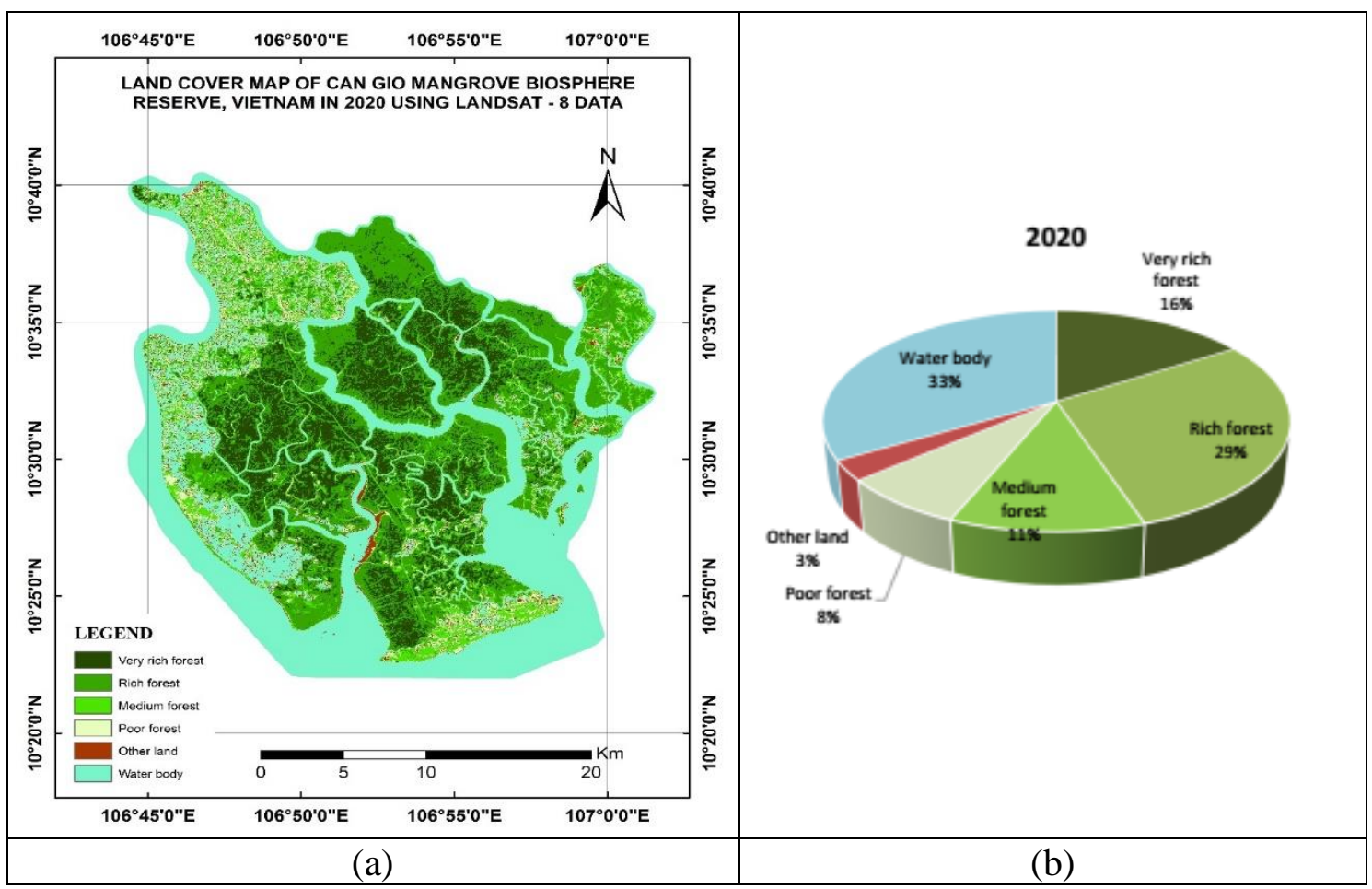

Figure 9. (a) Land cover map and (b) area distribution in the Can Gio Biosphere Reserve in 2020

Table 13. Statistics on the land cover area in the Can Gio Biosphere Reserve in 2020

\begin{tabular}{c|c|c|c|c}
\hline \multirow{2}{*}{ No. } & \multirow{2}{*}{ Main-class } & Sub-class & \multicolumn{2}{|c}{ Area } \\
\cline { 3 - 4 } & & ha & \% \\
\hline 1 & & Very rich forest & 11994.93 & 15.98 \\
2 & \multirow{3}{*}{ Forest } & Rich forest & 21659.20 & 28.86 \\
3 & & Medium forest & 8572.88 & 11.42 \\
4 & & Poor forest & 5578.09 & 7.43 \\
& & Sub-total & $\mathbf{4 7 8 0 5 . 1 0}$ & $\mathbf{6 3 . 7 0}$ \\
\hline 5 & \multirow{3}{*}{ Non-forest } & Other land & 2198.27 & 2.93 \\
6 & & Water body & 25045.39 & 33.37 \\
& & Sub-total & $\mathbf{2 7 2 4 3 . 6 6}$ & $\mathbf{3 6 . 3 0}$ \\
& & Total & $\mathbf{7 5 0 4 8 . 7 6}$ & $\mathbf{1 0 0 . 0 0}$ \\
\hline
\end{tabular}

\section{Land cover area change in the Can Gio Biosphere Reserve}

For a detailed assessment of forest changes in this study area, we have tried to select the satellite data with two-time intervals of 5 years and similar to the time of year satellite image acquisition and drop in the period of a national forest inventory of 
Vietnam, every five years. Therefore, in this study, we have selected Landsat satellite image data of 1995, 2000, 2005, 2010, 2015 and 2020 for mangrove change analysis. In this study, we also included temporary regulations for the criteria of positive and negative mangrove forest changes such as: (i) Non-change is the area unchanged; (ii) Negative area changes including; very rich forest (VRF) to rich forest (RF), very rich forest (VRF) to medium forest (MF), very rich forest (VRF) to poor forest (PF), very rich forest (VRF) to other land (OL), very rich forest (VRF) to water body (WB) along with rich forest (RF) to medium forest (MF), rich forest (RF) to poor forest (PF), rich forest $(\mathrm{RF})$ to other land (OL), rich forest $(\mathrm{RF})$ to water body (WB); poor forest (PF) to other land (OL), poor forest (PF) to water body (WB); (iii) Positive area change including; rich forest (RF) to very rich forest (VRF), medium forest (MF) to very rich forest (VRF), medium forest (MF) to rich forest (RF); poor forest (PF) to very rich forest (VRF), medium forest (MF) to rich forest (RF); other land (OL) to very rich forest (VRF), other land (OL) to rich forest (RF); other land (OL) to medium forest $(\mathrm{MF})$, other land (OL) to poor forest (PF); water body (WB) to very rich forest (VRF), water body (WB) to rich forest (RF), water body (WB) to medium forest (MF), water body (WB) to poor forest (PF), water body (WB) to other land (OL).

The statistical results of the land cover area change in the Can Gio Biosphere Reserve, HCMC, Vietnam over the periods such as 1995-2000, 2000-2005, 20052010, 2010-2015 and 2015-2020 are shown below.

\section{$1995-2000$}

Statistics from the land cover change matrix have shown that the non-change area is $5076.09(6.76 \%)$, the negative area change is $17196.39(22.91 \%)$, and the positive area change is $52776.28(70.32 \%)$. The detailed statistical results of the land cover area changes in the Can Gio Biosphere Reserve (CGMBR), HCMC, Vietnam over the period from 1995 to 2000 are shown in Figure 10 and Table 14.

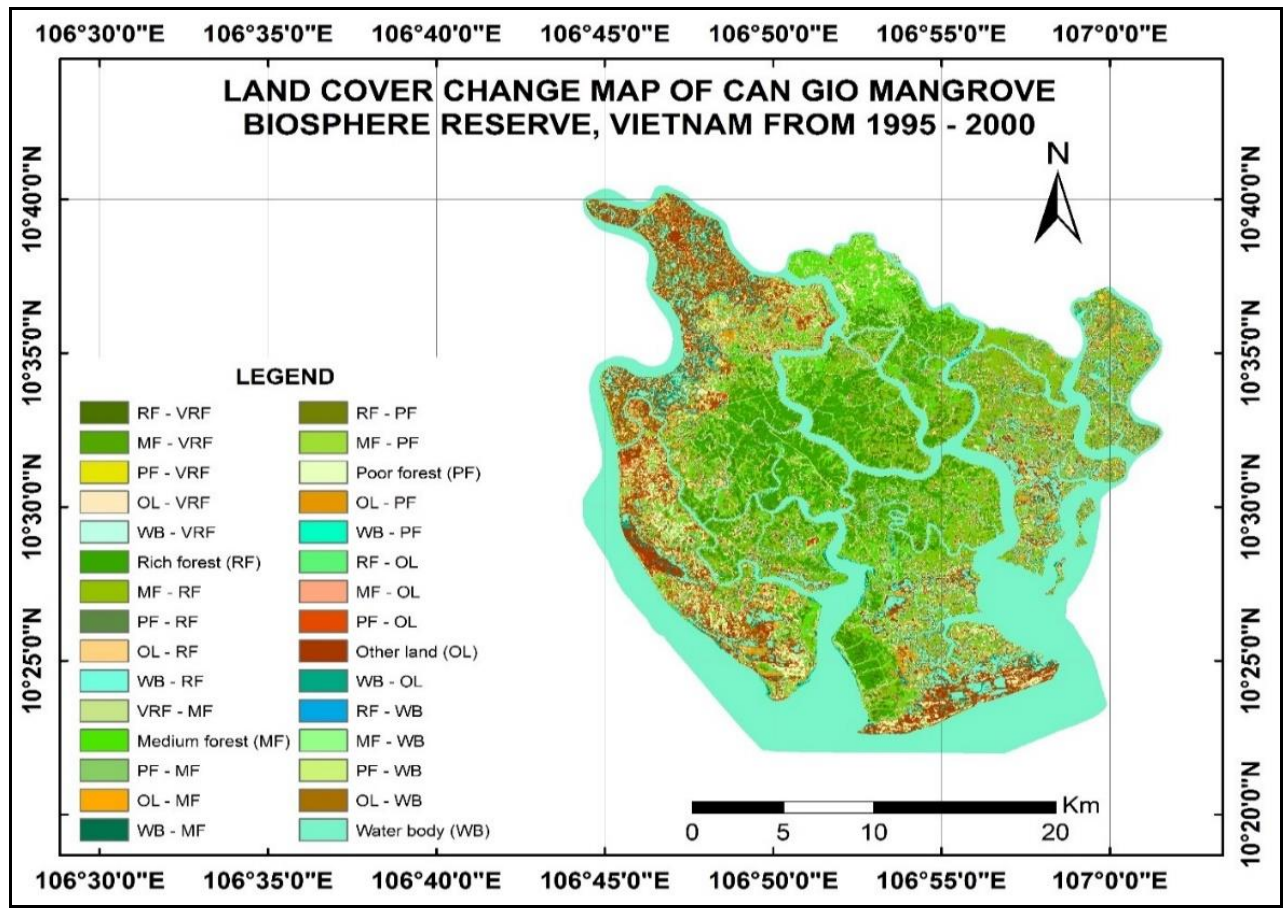

Figure 10. Land cover change map of the Can Gio Biosphere Reserve from 1995-2000 


$$
\text { - } 3915 \text { - }
$$

Table 14. The direction of land cover changes in the CGMBR from 1995-2000 (units: ha)

\begin{tabular}{c|c|c|c}
\hline \multirow{2}{*}{ No. } & Class & \multicolumn{2}{|c}{ Area } \\
\cline { 3 - 4 } & & ha & \% \\
\hline 1 & Non-change area & 5076.09 & 6.76 \\
2 & Negative area change & 17196.39 & 22.91 \\
3 & Positive area change & 52776.28 & 70.32 \\
& Total & $\mathbf{7 5 0 4 8 . 7 6}$ & $\mathbf{1 0 0 . 0 0}$ \\
\hline
\end{tabular}

\section{$2000-2005$}

Statistics from the land cover change matrix have shown that the non-change area is $49155.12(65.50 \%)$, the negative area change is $5765.04(7.68 \%)$, and the positive area change is $20128.60(26.82 \%)$. The detailed statistical results of the land cover area changes in the Can Gio Biosphere Reserve, HCMC, Vietnam over the period from 2000 to 2005 are shown in Figure 11 and Table 15.

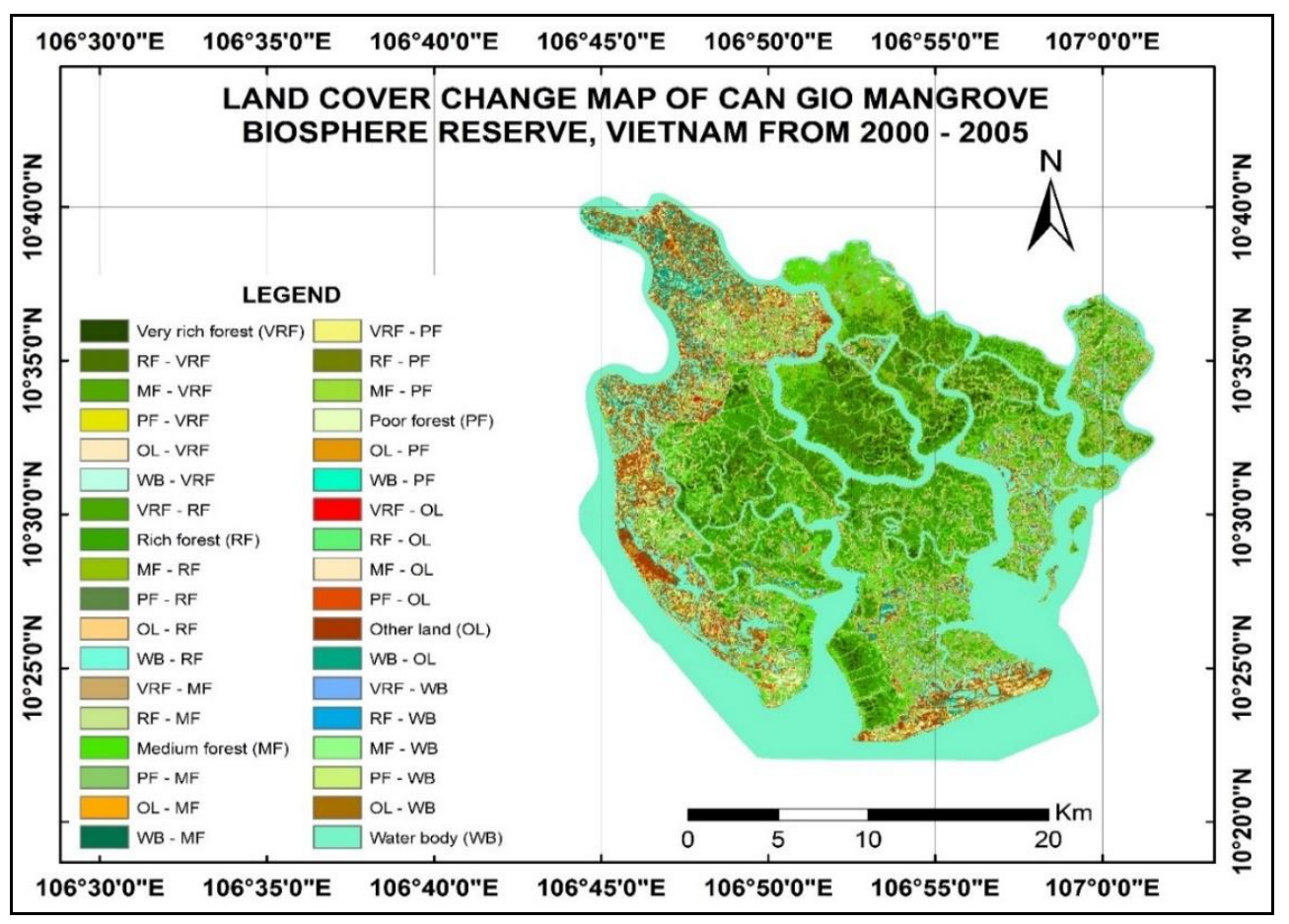

Figure 11. Land cover change map of the Can Gio Mangrove Biosphere Reserve from 20002005

Table 15. The direction of land cover changes in the CGMBR from 2000-2005 (units: ha)

\begin{tabular}{c|c|c|c}
\hline \multirow{2}{*}{ No. } & Class & \multicolumn{2}{|c}{ Area } \\
\cline { 3 - 4 } & & ha & \% \\
\hline 1 & Non-change area & 49155.12 & 65.50 \\
2 & Negative area change & 5765.04 & 7.68 \\
3 & Positive area change & 20128.60 & 26.82 \\
& Total & $\mathbf{7 5 0 4 8 . 7 6}$ & $\mathbf{1 0 0 . 0 0}$ \\
\hline
\end{tabular}




\section{$2005-2010$}

Statistics from the land cover change matrix have shown that the non-change area is $48464.64(64.58 \%)$, the negative area change is $7094.16(9.45 \%)$, and the positive area change is $19489.96(25.97 \%)$. The detailed statistical results of the land cover area changes in the Can Gio Biosphere Reserve, HCMC, Vietnam over the period from 2005 to 2010 are shown in Figure 12 and Table 16.

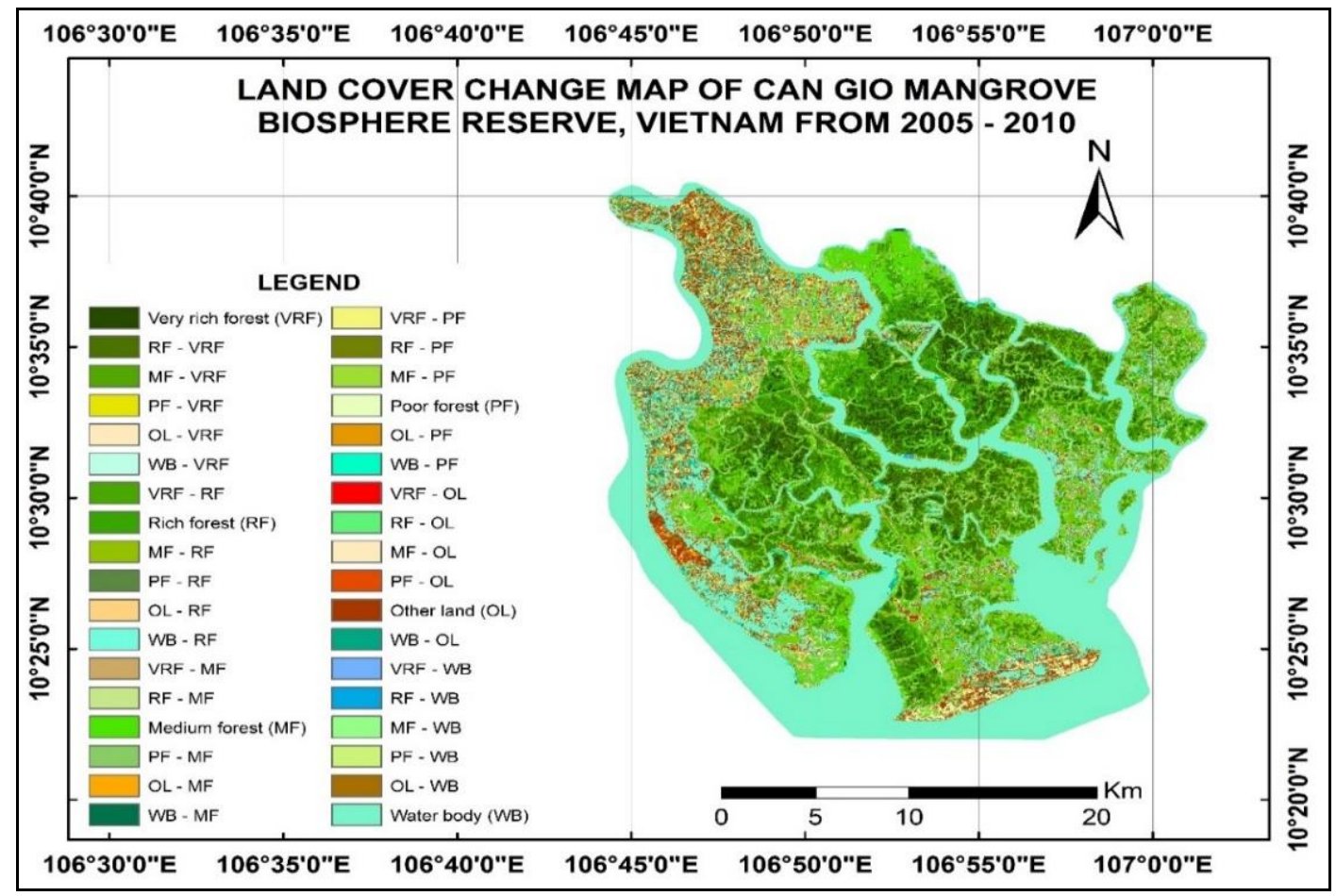

Figure 12. Land cover change map of the Can Gio Mangrove Biosphere Reserve from 20052010

Table 16. The direction of land cover changes in the CGMBR from 2005-2010 (units: ha)

\begin{tabular}{c|c|c|c}
\hline \multirow{2}{*}{ No. } & Class & \multicolumn{2}{|c}{ Area } \\
\cline { 3 - 4 } & & ha & \% \\
\hline 1 & Non-change area & 48464.64 & 64.58 \\
2 & Negative area change & 7094.16 & 9.45 \\
3 & Positive area change & 19489.96 & 25.97 \\
& Total & $\mathbf{7 5 0 4 8 . 7 6}$ & $\mathbf{1 0 0 . 0 0}$ \\
\hline
\end{tabular}

\section{$2010-2015$}

Statistics from the land cover change matrix have shown that the non-change area is $46234.62(61.61 \%)$, the negative area change is $8647.20(11.52 \%)$, and the positive area change is $20166.94(26.87 \%)$. The detailed statistical results of the land cover area changes in the Can Gio Biosphere Reserve, HCMC, Vietnam over the period from 2010 to 2015 are shown in Figure 13 and Table 17. 


$$
\text { - } 3917 \text { - }
$$

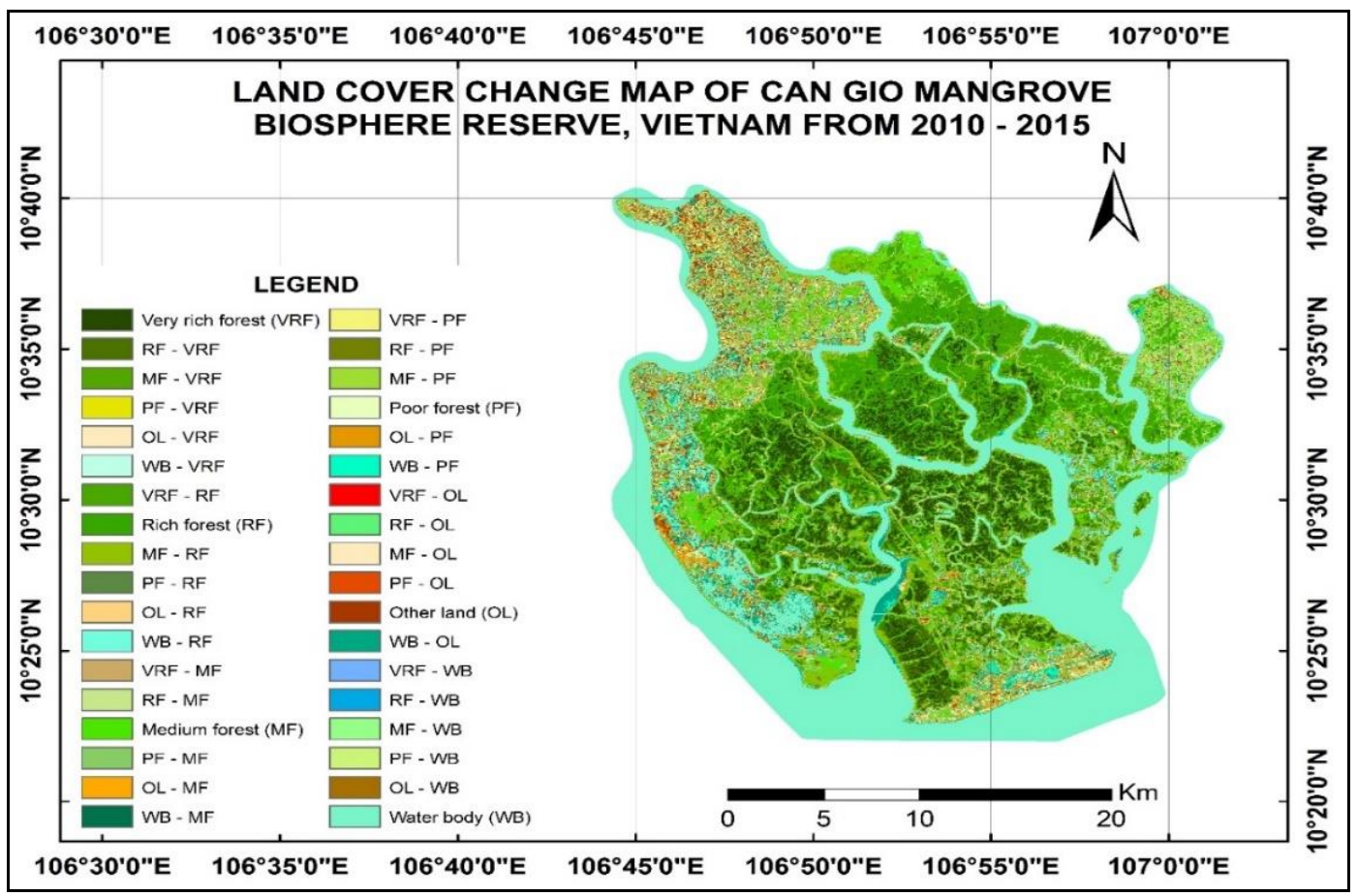

Figure 13. Land cover change map of the Can Gio Mangrove Biosphere Reserve from 20102015

Table 17. The direction of land cover changes in the CGMBR from 2010-2015 (units: ha)

\begin{tabular}{c|c|c|c}
\hline \multirow{2}{*}{ No. } & Class & \multicolumn{2}{|c}{ Area } \\
\cline { 3 - 4 } & & 46234.62 & ha \\
\hline 1 & Non-change area & 8647.20 & 61.61 \\
2 & Negative area change & 20166.94 & 11.52 \\
3 & Positive area change & $\mathbf{7 5 0 4 8 . 7 6}$ & 26.87 \\
& Total & $\mathbf{1 0 0 . 0 0}$ \\
\hline
\end{tabular}

\section{$2015-2020$}

Statistics from the land cover change matrix have shown that the non-change area is $50787.58(67.67 \%)$, the negative area change is $5759.35(7.67 \%)$, and the positive area change is $18501.84(24.65 \%)$. The detailed statistical results of the land cover area changes in the Can Gio Biosphere Reserve, HCMC, Vietnam over the period from 2015 to 2020 are shown in Figure 14 and Table 18.

Table 18. The direction of land cover changes in the CGMBR from 2015-2020 (units: ha)

\begin{tabular}{c|c|c|c}
\hline \multirow{2}{*}{ No. } & Class & \multicolumn{2}{|c}{ Area } \\
\cline { 3 - 4 } & & ha & \% \\
\hline 1 & Non-change area & 50787.58 & 67.67 \\
2 & Negative area change & 5759.35 & 7.67 \\
3 & Positive area change & 18501.84 & 24.65 \\
& Total & $\mathbf{7 5 0 4 8 . 7 6}$ & $\mathbf{1 0 0 . 0 0}$ \\
\hline
\end{tabular}




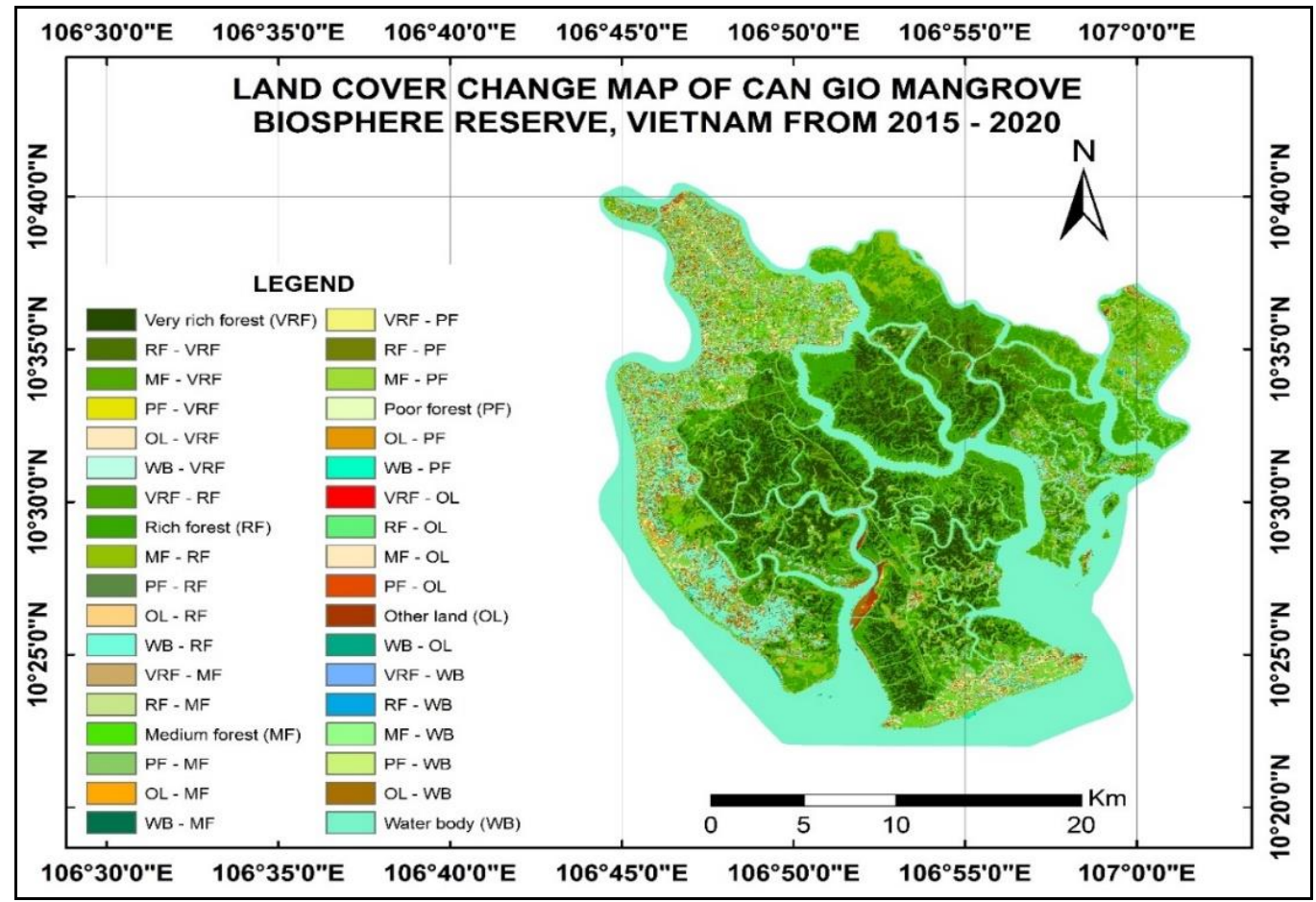

Figure 14. Land cover change map of the Can Gio Mangrove Biosphere Reserve from 20152020

\section{Detection of parameters of mangrove structures using satellite data}

Data such as the backscatter density of HV, HH polarization from the ALOS-2 PALSAR-2 image and NDVI from Landsat 8 image, were extracted for the analysis of the relationship with the parameters of mangrove structure such as basal area $(\mathrm{G})$, height $(\mathrm{H})$, density $(\mathrm{N})$ and biomass (AGB).

\section{Using single-satellite sensor}

The sensitivity of NDVI value from Landsat 8 (NDVI_LS8) image to different parameters of mangrove forest $(\mathrm{G}, \mathrm{H}, \mathrm{N}$ and AGB) was statistically analysed using simple linear regression models, (a) Polynomial model (black colour), (b) Linear model (red colour) and (c) Exponential model (blue colour). The coefficient of determination $\left(\mathrm{R}^{2}\right)$ and root mean square error (RMSE) were used as the metrics for evaluating the relationships. A total of 12 models were analysed (Fig. 15). The result of the relationship between basal area $\left(\mathrm{m}^{2} / \mathrm{ha}\right)$ and Normalised Difference Vegetation Index from Landsat 8 (NDVI_L8) using polynomial model, linear model and exponential model is $\left(\mathrm{R}^{2}=0.58\right),\left(\mathrm{R}^{2}=0.56\right),\left(\mathrm{R}^{2}=0.61\right)$ equivalent (Fig. 15.1).

The result of the relationship between height tree $(\mathrm{m} / \mathrm{ha})$ and NDVI using the polynomial model, linear model and exponential model is $\left(\mathrm{R}^{2}=0.30\right),\left(\mathrm{R}^{2}=0.30\right),\left(\mathrm{R}^{2}=0.30\right)$ equivalent (Fig. 15.2). The result of the relationship between density (tree/ha) and NDVI using the polynomial model, linear model and exponential model is $\left(\mathrm{R}^{2}=0.17\right),\left(\mathrm{R}^{2}=0.17\right)$, $\left(\mathrm{R}^{2}=0.19\right)$ equivalent (Fig. 15.3). The result of the relationship between biomass (ton/ha) and NDVI using polynomial model, linear model and exponential model is $\left(\mathrm{R}^{2}=0.65\right)$, $\left(\mathrm{R}^{2}=0.60\right)$, $\left(\mathrm{R}^{2}=0.63\right)$ equivalent (Fig. 15.4). The best results obtained with each parameter of mangrove structures from NDVI are shown in Table 19. 


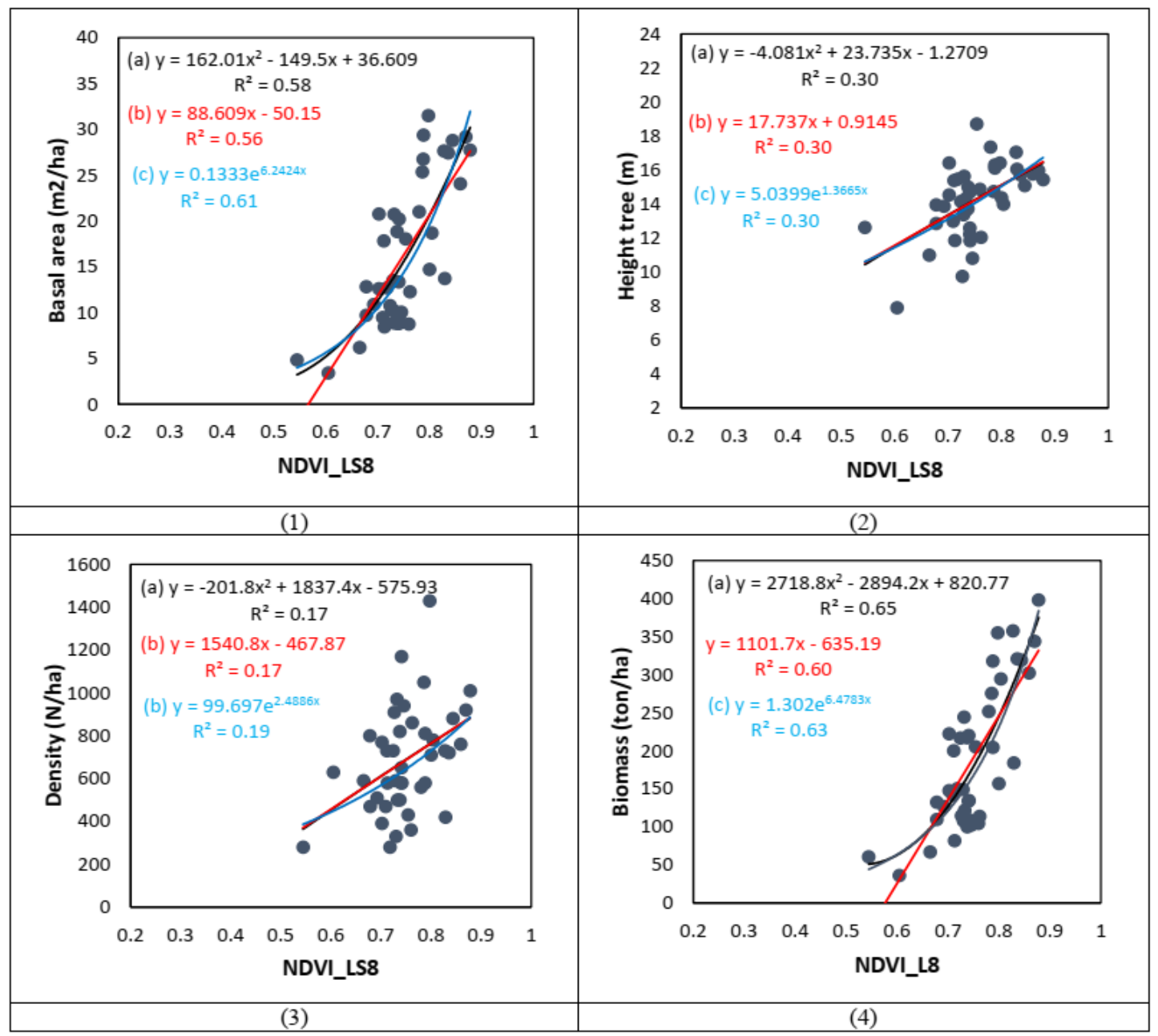

Figure 15. The relationship between parameters of mangrove structure and NDVI values; (1) Basal area \& NDVI, (2) Tree height \& NDVI, (3) Tree density \& NDVI and (4) Biomass \& $N D V I$

Table 19. The best results obtained with each parameter of mangrove structure from NDVI value (Landsat 8)

\begin{tabular}{c|c|c|c|c}
\hline No. & Model & $\mathbf{R}^{2}$ & RMSE & Ref. figure \\
\hline 1 & Basal area $\left(\mathrm{m}^{2} / \mathrm{ha}\right)=162.01 * \mathrm{NDVI}^{2}-149.5 * \mathrm{NDVI}+36.609$ & 0.58 & 3.30 & $15.1 .(\mathrm{a})$ \\
2 & Height tree $(\mathrm{m})=-4.081 * \mathrm{NDVI}^{2}+23.735 * \mathrm{NDVI}-1.2709$ & 0.30 & 1.50 & $15.2 .(\mathrm{b})$ \\
3 & Density (tree/ha) $=99.697 \mathrm{e}^{2.4886 x}$ & 0.19 & 199 & $15.3 .(\mathrm{a})$ \\
4 & Biomass (ton/ha) $=2718.8 * \mathrm{NDVI}^{2}-2894.2 * \mathrm{NDVI}+820.77$ & 0.65 & 32.89 & $15.4 .(\mathrm{a})$ \\
\hline
\end{tabular}

Similarly, the sensitivity of backscatter density $(\mathrm{HH})$ to different parameters of mangrove forest $(\mathrm{G}, \mathrm{H}, \mathrm{N}$ and $\mathrm{AGB}$ ) was statistically analysed using simple linear regression models, (a) Polynomial model (black colour), (b) Linear model (red colour) and (c) Exponential model (blue colour). A total of 12 models were analysed (Fiure 16). The result of the relationship between basal area $\left(\mathrm{m}^{2} / \mathrm{ha}\right)$ and $\mathrm{HH}$ backscattering intensity $\left(\sigma^{\circ}\right)$ using polynomial model, linear model and exponential model is 
$\left(\mathrm{R}^{2}=0.34\right),\left(\mathrm{R}^{2}=0.29\right),\left(\mathrm{R}^{2}=0.22\right)$ equivalent (Fig. 16.1). The result of the relationship between height tree $(\mathrm{m})$ and $\mathrm{HH}$ backscattering intensity $\left(\sigma^{\circ}\right)$ using polynomial model, linear model and exponential model is $\left(\mathrm{R}^{2}=0.17\right),\left(\mathrm{R}^{2}=0.17\right),\left(\mathrm{R}^{2}=0.16\right)$ equivalent (Fig. 16.2). The result of the relationship between density (tree/ha) and $\mathrm{HH}$ backscattering intensity $\left(\sigma^{\circ}\right)$ using polynomial model, linear model and exponential model is $\left(\mathrm{R}^{2}=0.07\right),\left(\mathrm{R}^{2}=0.01\right)$, $\left(\mathrm{R}^{2}=0.01\right)$ equivalent (Fig. 16.3). The result of the relationship between biomass (ton/ha) and HH backscattering intensity $\left(\sigma^{\circ}\right)$ using polynomial model, linear model and exponential model is $\left(\mathrm{R}^{2}=0.42\right),\left(\mathrm{R}^{2}=0.37\right)$, $\left(\mathrm{R}^{2}=0.27\right.$ ) equivalent (Fig. 16.4). The best results obtained with each parameter of mangrove structures from $\mathrm{HH}$ polarization are shown in Table 20.

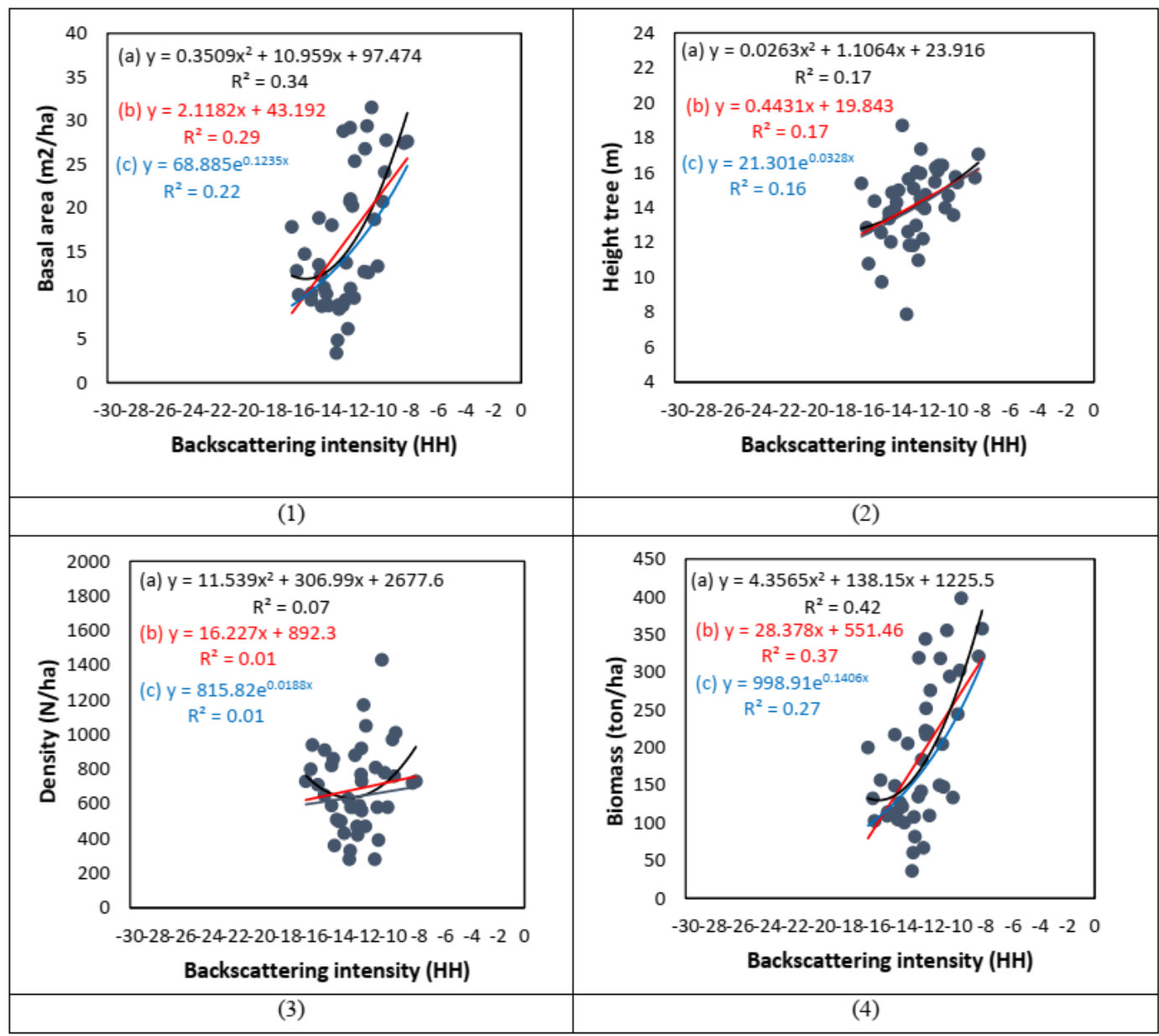

Figure 16. The relationship between parameters of mangrove structure and HH polarization; (1) Basal area \& HH, (2) Tree height \& HH, (3) Tree density \& HH and (4) Biomass \& HH

Table 20. The best results obtained with each parameter of mangrove structure from $\mathrm{HH}$ backscattering intensity

\begin{tabular}{c|c|c|c|c}
\hline No. & Model & $\mathbf{R}^{\mathbf{2}}$ & RMSE & Ref. figure \\
\hline 1 & Basal area $\left(\mathrm{m}^{2} / \mathrm{ha}\right)=0.3509 * \mathrm{HH}^{2}+10.959 * \mathrm{HH}+97.474$ & 0.34 & 5.18 & $16.1 .(\mathrm{a})$ \\
2 & Height tree $(\mathrm{m})=0.0263 * \mathrm{HH}^{2}+1.1064 * \mathrm{HH}+23.916$ & 0.17 & 1.78 & 16.2 (b) \\
3 & Density (tree/ha) $=11.539 * \mathrm{HH}^{2}+306.99 * \mathrm{HH}+2677.6$ & 0.07 & 228 & $16.3 .(\mathrm{a})$ \\
4 & Biomass (ton $/ \mathrm{ha})=4.3565 * \mathrm{HH}^{2}+138.15 * \mathrm{HH}+1225.5$ & 0.42 & 54.50 & 16.4 .(a) \\
\hline
\end{tabular}


After the previously mentioned analysis, the relationship between the backscatter density (HV) and the parameters of mangrove structure (G, H, N and AGB) was also analysed. The sensitivity of backscatter density (HV) to different parameters of mangrove forest was statistically analysed using simple linear regression models, (a) Polynomial model (black colour); (b) Linear model (red colour) and (c) Exponential model (blue colour). A total of 12 models were analysed (Figure 17). The result of the relationship between basal area $\left(\mathrm{m}^{2} / \mathrm{ha}\right)$ and $\mathrm{HV}$ backscattering intensity $\left(\sigma^{\circ}\right)$ using polynomial model, linear model and exponential model is $\left(\mathrm{R}^{2}=0.81\right),\left(\mathrm{R}^{2}=0.74\right)$, $\left(\mathrm{R}^{2}=0.66\right)$ equivalent (Fig. 17.1). The result of the relationship between height tree $(\mathrm{m})$ and $\mathrm{HV}$ backscattering intensity $\left(\sigma^{\circ}\right)$ using polynomial model, linear model and exponential model is $\left(\mathrm{R}^{2}=0.50\right),\left(\mathrm{R}^{2}=0.45\right),\left(\mathrm{R}^{2}=0.43\right)$ equivalent (Fig. 17.2). The result of the relationship between density (tree/ha) and HV backscattering intensity $\left(\sigma^{\circ}\right)$ using polynomial model, linear model and exponential model is $\left(\mathrm{R}^{2}=0.34\right),\left(\mathrm{R}^{2}=0.16\right)$, $\left(\mathrm{R}^{2}=0.13\right.$ ) equivalent (Fig. 17.3). The result of the relationship between biomass (ton/ha) and HV backscattering intensity $\left(\sigma^{\circ}\right)$ using polynomial model, linear model and exponential model is $\left(\mathrm{R}^{2}=0.77\right),\left(\mathrm{R}^{2}=0.72\right),\left(\mathrm{R}^{2}=0.65\right)$ equivalent (Fig. 17.4). The best results obtained with each parameter of mangrove structures from $\mathrm{HV}$ polarization are shown in Table 21.

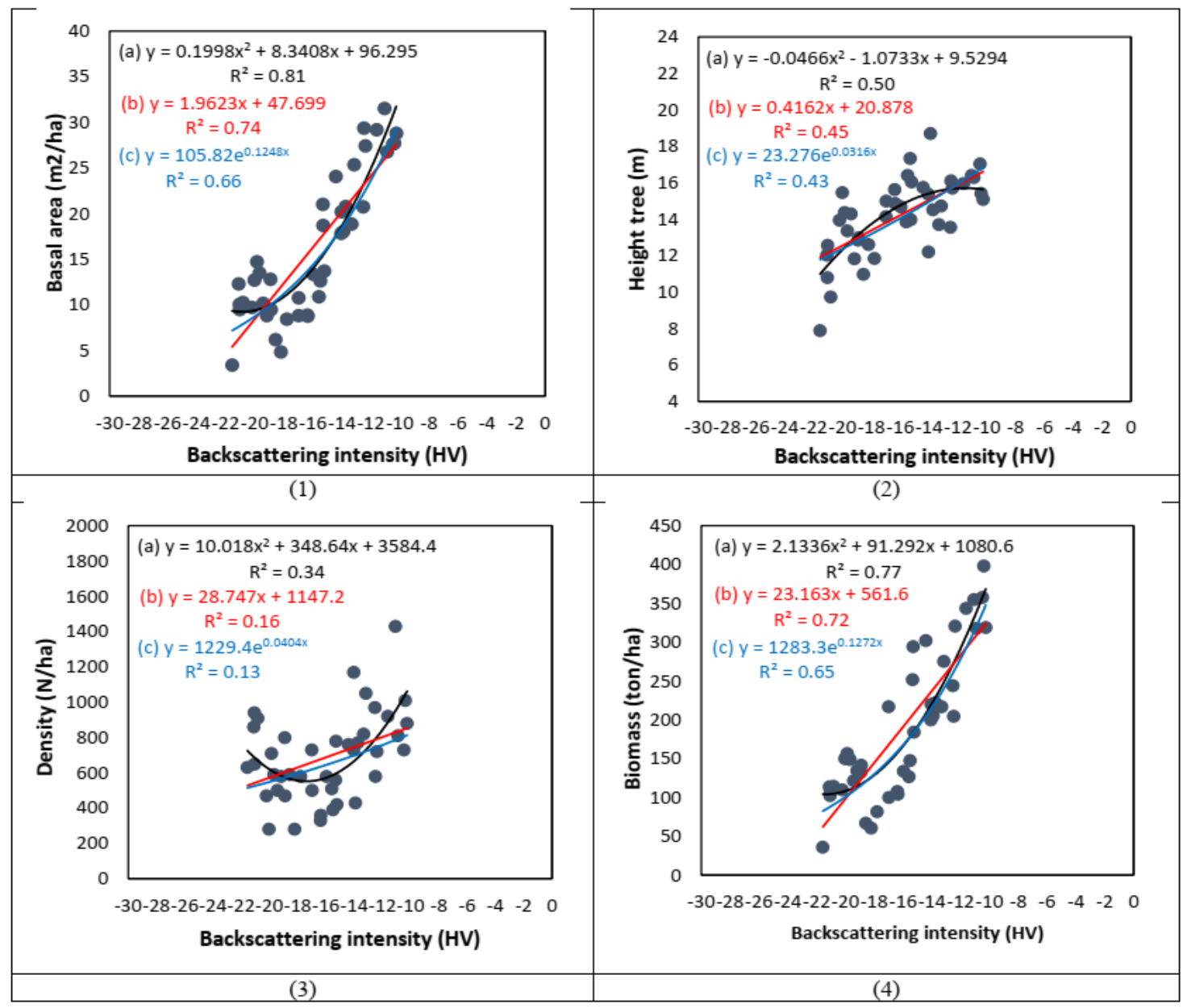

Figure 17. The relationship between parameters of mangrove structure and $H V$ polarization; (1) Basal area \& HV, (2) Tree height \& HV, (3) Tree density \& HV and (4) Biomass \& $H V$ 
Table 21. The best results obtained with each parameter of mangrove structure from $\mathrm{HV}$ backscattering intensity

\begin{tabular}{c|c|c|c|c}
\hline No. & Model & $\mathbf{R}^{2}$ & RMSE & Ref. figure \\
\hline 1 & $\mathrm{G}\left(\mathrm{m}^{2} / \mathrm{ha}\right)=0.1998 * \mathrm{HV}^{2}+8.3408 * \mathrm{HV}+96.295$ & 0.81 & 1.49 & $17.1 .(\mathrm{a})$ \\
2 & Height tree $(\mathrm{m})=-0.0466 * \mathrm{HV}^{2}-1.0733 * \mathrm{HV}+9.5294$ & 0.50 & 1.07 & 17.2 .(b) \\
3 & Density (tree/ha) $=10.018 * \mathrm{HV}^{2}+348.64 * \mathrm{HV}+3584.4$ & 0.34 & 162 & $17.3 .(\mathrm{a})$ \\
4 & Biomass (ton $/ \mathrm{ha})=2.1336 * \mathrm{HV}^{2}+91.292 * \mathrm{HV}+1080.6$ & 0.77 & 21.61 & $17.4 .(\mathrm{a})$ \\
\hline
\end{tabular}

\section{Using combined satellite sensors}

We combined the HV backscattering intensity $\left(\sigma^{\circ}\right)$ and eight textures (contrast, correlation, dissimilarity, entropy, homogeneity, mean, second moment, variance) from ALOS-2 PALSAR-2 and spectral (NDVI) from Landsat 8. The sensitivity of the spectral/backscattering to different parameters of mangrove forest was statistically analysed using multiple linear regression models. The coefficient of determination $\left(\mathrm{R}^{2}\right)$ and root mean square error (RMSE) were used as the metrics for evaluating the relationships. A total of 4 models were analysed, and these models can explain mangrove structural parameters such as the basal area of $91 \%\left(\mathrm{R}^{2}=0.91, \mathrm{RMSE}=0.71\right)$, the height of $60 \%\left(\mathrm{R}^{2}=0.60, \mathrm{RMSE}=0.86\right)$, the density of $52 \%\left(\mathrm{R}^{2}=0.52, \mathrm{RMSE}=118\right)$ and the biomass of $91 \%\left(\mathrm{R}^{2}=0.91\right.$, RMSE $\left.=8.46\right)$ by satellite data (NDVI, HV backscattering intensity and eight textures) the results obtained with each parameter of mangrove structure, in this case, are shown in Table 22.

Table 22. The results obtained with each parameter of mangrove structure using NDVI value and textures and backscattering intensity from $H V$ polarization

\begin{tabular}{|c|c|c|c|}
\hline No. & Model & $\mathbf{R}^{2}$ & RMSE \\
\hline 1 & $\begin{array}{c}\text { Basal area }\left(\mathrm{m}^{2}\right)=-326.43+1.55 * \mathrm{HV}+38.90 * \mathrm{NDVI}-1.57-1.57 * \mathrm{HV} \_ \text {Mean-1.02* } \\
\text { HV_Variance }+14.60 * \mathrm{HV} \text { _Homogeneity-0.16*HV_Contrast }+8.32 * \\
\text { HV_Dissimilarit }+100.83 * \text { HV_Entropy }+1320.82 * \text { HV_SecondMoment }+6.75^{*} \\
\text { HV_Correlation }\end{array}$ & 0.91 & 0.71 \\
\hline 2 & $\begin{array}{c}\text { Height } \\
(\mathrm{m})=31.65+0.24 \mathrm{HV}+11.05 * \text { LS8_NDVI }+0.46 * \mathrm{HV} \_ \text {Mean }+0.22 * \mathrm{HV} \text { _Variance- } \\
2.32 * \text { HV_Homogeneity-0.14*HV_Contrast }+0.98 * \mathrm{HV} \_ \text {Dissimilarit-11.51* } \\
\text { HV_Entropy-99.34* HV_SecondMoment-1.40* HV_Correlation }\end{array}$ & 0.60 & 0.86 \\
\hline 3 & $\begin{array}{c}\text { Density (tree/ha) }=-18422.71+20.29 * \text { HV }+1114.47 * \text { LS8_NDVI-59.32* HV_Mean- } \\
60.52 * \text { HV_Variance }+981.75 * \text { HV_Homogeneity }+3.93 * \text { HV_Contrast }+223.83 * \\
\text { HV_Dissimilarit }\end{array}$ & 0.52 & 118 \\
\hline 4 & $\begin{array}{c}\text { Biomass (ton/ha) }=-4580.94+16.00 * \text { HV }+618.47 * \text { LS8_NDVI--2.56* } \\
\text { HV_Mean }+1.18 * \text { HV_Variance }+701.63 * \text { HV_Homogeneity-15.78* } \\
\text { HV_Contrast }+202.59 * \text { HV_Dissimilarit }+1118.49 * \text { HV_Entropy }+12928.88^{*} \\
\text { HV_SecondMoment-38.33* HV_Correlation }\end{array}$ & 0.91 & 8.46 \\
\hline
\end{tabular}

\section{Discussion}

The results present a general, detailed and clear overview of the mangrove area as well as the dynamic analysis of the mangrove cover in the study area for nearly 5 decades (1972-2020). It was discovered and recorded using the image series from 
Landsat satellites such as Landsat 1 (1972), Landsat 5 (1988, 1995, 2000, 2005), Landsat 7 (2010) and Landsat 8 (2015, 2020). The research results are as follows:

In 1972, this study area did not show the very rich forests, the rich forests and the medium forests; only poor forests' status was indicated with an area of 7,158.15 ha $(9.54 \%)$ because the mangrove forest was destroyed by the US military's chemical warfare (1965-1970). The land cover information from our results were not very different from the traditional survey results. The forest covers about $6.3 \%$ of the natural land area of Can Gio district; the vegetation in the remaining area was in a very poor condition, and it consisted of saplings of Lumnitzera racemosa, Excoecaria agallocha, Ceriops tagal and Ceriops decandra. In other areas, nothing was to be seen other than shrubs of Acanthus spp., Derris trifoliata, Finlaysonia obovata, Acrostichum aureum, etc., with a maximum height of $2 \mathrm{~m}$ (Hong, 2001; Tuam, 2002).

In 1988, after 16 years of afforestation (plantation started in 1978), medium mangroves appeared, with an area of 6695.46 ha $(8.92 \%)$, together with the poor forest area, which was 19170.00 ha $(25.54 \%)$, increasing the total forest cover in the study area to $34.46 \%$.

In 1995, the recorded area of rich forest was 8995.05 ha $(11.99 \%)$, with the medium forest at 13205.43 ha $(17.60 \%)$ and the poor forest at 12578.85 ha $(16.76 \%)$, increasing the total forest cover in the study area to $46.34 \%$.

In 2000 (recognised by MAB/UNESCO as the first biosphere reserve in Vietnam), after 22 years of restoration, a very rich forest area was recorded at 1625.58 ha $(2.17 \%)$; the rich forest was 15122.61 ha $(20.15 \%)$, the medium forest was 11724.88 ha $(15.62 \%)$ and the poor forest was 10375.16 ha $(13.82 \%)$, increasing the total forest cover in the study area to $51.76 \%$. At this time, the medium and poor forest areas were lower than in 1995 because some of these forests were converted to rich and medium forests.

In 2005, the very rich forest area was recorded at 4892.91 ha $(6.52 \%)$; the rich forest area was 15382.35 ha $(20.50 \%)$, the medium forest area was 11888.77 ha $(15.84 \%)$, and the poor forest area was 8567.19 ha $(11.42 \%)$, which increased the total forest cover in the study area to $54.27 \%$. At this time, the mangrove forest was relatively stable in the area as compared to the period before 2000 .

In 2010, the very rich forest area was recorded at 9433.27 ha $(12.57 \%)$; the rich forest area was 15121.80 ha $(20.15 \%)$, the medium forest area was 11152.53 ha $(14.86 \%)$, and the poor forest area was 7016.67 ha $(9.35 \%)$. At this time, the area of the rich forest increased by about $20 \%$ as compared to 2005 , leading to an increase in the total forest cover of the study area to $56.93 \%$.

In 2015 , the very rich forest area was recorded at 10161.18 ha $(13.54 \%)$; the rich forest area was 18728.36 ha $(24.96 \%)$, the medium forest area was 9355.57 ha $(12.47 \%)$, and the poor forest area was 6717.47 ha $(8.95 \%)$. Overall, the forest cover increased to $59.91 \%$.

Finally, in 2020, the very rich forest area was 11994.93 ha (15.98\%); the rich forest area was 21659.20 ha $(28.86 \%)$, the medium forest area was 8572.88 ha (11.42\%), and the poor forest was 5578.09 ha $(7.43 \%)$. The forest cover in the Can Gio Biosphere Reserve now reached $63.70 \%$.

The results of the analysis based on the change of each mangrove forest type are as follows: for the poor forest type, it was $9.54 \%$ in $1972,25.54 \%$ in $1988,16.76 \%$ in $1995,13.82 \%$ in $2000,15.84 \%$ in $2005,9.35 \%$ in $2010,8.95 \%$ in 2015 and $7.43 \%$ in 2020. The area of poor forests increased from 1972 to 2005 and then decreased from 2010 to 2020 because some parts of the poor forests were converted to better forests 
such as medium, rich and very rich forests. The medium forest type was missing in 1972 and increased to $8.92 \%$ in $1988,17.60 \%$ in $1995,15.62 \%$ in $2000,15.84 \%$ in $2005,14.86 \%$ in $2010,12.47 \%$ in 2015 and $11.42 \%$ in 2020 . This type of forest underwent little change (except in 1998) because the mangrove forest area conversion in positive and negative ways was in balance. Regarding the rich forest type, the data is follows: 1972 (did not appear),1988 (did not appear), 1995 (11.99\% with 8995.05 ha), 2000 (20.15\%), 2005 (20.50\%), 2010 (20.15\%), 2015 (24.96\%) and 2020 (28.86\%). This mangrove forest had a stable area from 2000 onwards, accounting for more than $20 \%$ of the total area. The very rich mangrove forest did not appear from 1972 to 1995. In 2000 , a small area of 1625.58 ha $(2.17 \%)$ was recorded, which increased to $6.52 \%$ in $2005,12.57 \%$ in $2010,13.54 \%$ in 2015 and $15.98 \%$ in 2020 . This type of mangrove forest area increased significantly from 2000 to 2010, but from 2010 to 2020, it did not change much because of the following reasons: (i) over maturation of the forest; (ii) the forest was not thinned for 42 years after plantation and (iii) the phenomenon of ageing, along with pests, tropical storms etc. (Diele et al., 2013; Nam et al., 2014).

The analysis of the trend of land cover changes in the area at different times of the study is as follows: (i) the non-change areas (ha and \%) are 5076.09 ha/6.76\% (19952000), 49155.12 ha/65.50\% (2000-2005), 48464.64 ha/64.58\% (2005-2010), $46234.62 \mathrm{ha} / 61.61 \%(2010-2015)$ and $50787.58 \mathrm{ha} / 67.67 \%$ (2015-2020); (ii) the negative area changes (ha and \%) are $17196.39 \mathrm{ha} / 22.91 \%(1995-2000), 5765.04$ ha/7.68\% (2000-2005), 7094.16 ha/9.45\% (2005-2010), 8647.20 ha/11.52\% (20102015 ) and $5759.35 \mathrm{ha} / 7.67 \%$ (2015-2020); (iii) the positive area changes (ha and \%) are $52776.28 \mathrm{ha} / 70.32 \%$ (1995-2000), $20128.60 \mathrm{ha} / 26.82 \%$ (2000-2005), 19489.96 ha/25.97\% (2005-2010), $20166.94 \mathrm{ha} / 26.87 \%$ (2010-2015) and $18501.84 \mathrm{ha} / 24.65 \%$ (2015-2020).

In general, the coverage of the mangroves in the study area gradually increased over the years as follows: $9.54 \%$ in $1972,34.46 \%$ in $1988,46.34 \%$ in $1995,51.76 \%$ in 2000 , $54.27 \%$ in $2005,56.93 \%$ in $2010,59.91 \%$ in 2015 and, finally, $63.70 \%$ in 2020 .

To detect the parameters of mangrove structures using satellite data to find the best detecting model of forest parameters, this study conducted the research in the following different ways. First, we used a single-satellite sensor. Performance of NDVI value from Landsat 8 to detection of mangrove forest parameters are as follows: NDVI and basal area $\left(\mathrm{R}^{2}=0.58, \mathrm{RMSE}=3.30\right)$, NDVI and height tree $\left(\mathrm{R}^{2}=0.30\right.$, $\left.\mathrm{RMSE}=1.5\right)$, NDVI and density $\left(\mathrm{R}^{2}=0.19, \mathrm{RMSE}=199\right)$ and NDVI and biomass $\left(\mathrm{R}^{2}=0.65\right.$, RMSE $=32.89)$; $\mathrm{HH}$ backscattering and basal area $\left(\mathrm{R}^{2}=0.34, \mathrm{RMSE}=5.18\right), \mathrm{HH}$ backscattering and height $\left(\mathrm{R}^{2}=0.17, \mathrm{RMSE}=1.78\right)$, $\mathrm{HH}$ backscattering and density $\left(\mathrm{R}^{2}=0.07, \quad \mathrm{RMSE}=228\right)$ and $\mathrm{HH}$ backscattering and biomass $\left(\mathrm{R}^{2}=0.42\right.$, $\mathrm{RMSE}=54.50)$; $\mathrm{HV}$ backscattering and basal area $\left(\mathrm{R}^{2}=0.81, \mathrm{RMSE}=1.49\right), \mathrm{HV}$ backscattering and height $\left(\mathrm{R}^{2}=0.50, \mathrm{RMSE}=1.07\right), \mathrm{HV}$ backscattering and density $\left(\mathrm{R}^{2}=0.34, \quad \mathrm{RMSE}=162\right)$ and $\mathrm{HV}$ backscattering and biomass $\left(\mathrm{R}^{2}=0.42\right.$, RMSE = 54.50). The values of NDVI and HH backscattering are not highly effective in estimating the structure of mangrove forests. HV backscattering is better, but the detection of the density of trees is very low.

We used a multi-layered linear regression algorithm to improve the modelling of the mangrove structures by combining the multiple variables of NDVI values from Landsat 8 and HV backscattering, including Contrast, Correlation, Dissimilarity, Entropy, Homogeneity, Mean, Second Moment and Variance from ALOS-2 PALSAR-2. In this way, the combined models can improve the explanation of the mangrove structural 
parameters such as the basal area of $91 \%\left(\mathrm{R}^{2}=0.91, \mathrm{RMSE}=0.71\right)$, the height of $60 \%$ $\left(\mathrm{R}^{2}=0.60, \mathrm{RMSE}=0.86\right)$, the density of $52 \%\left(\mathrm{R}^{2}=0.52, \mathrm{RMSE}=118\right)$ and the biomass of $91 \%\left(\mathrm{R}^{2}=0.91, \mathrm{RMSE}=8.46\right)$ by satellite data. These results improved when compared with previous similar studies of Luong et al. (2016), Nguyen et al. (2016) and Luong et al. (2019) and some other studies such as Vu et al. (2014), Hamdan et al. (2014), Thuy et al. (2020).

In this study, the limitation lies in the lack of assessment of the herbicide content at the respective mangrove changes assessment periods, so it has not been able to evaluate the interaction effects between the rehabilitation of mangroves and herbicide concentrations in the soil here. This study also did not compare with the restoration of mangrove forests of other areas in Vietnam as well as other countries and territories around in the world. In addition, there was no comparison of the recovery of other tropical forest types. These will be our future research interests.

\section{Conclusions}

The challenges of climate change today are increasingly unpredictable and requires managers of forest resources, including mangroves, to gain appropriate silvicultural solutions for restoring, managing, conserving and sustainable development of the mangrove forests.

Currently, in Vietnam, a national forest inventory is conducted every 5 years, usually by the Institution of Forest Inventory and Planning (FIPI), and mangroves are classified as a single class, called "mangrove forest". This national forest inventory was not divided into classes such as very rich forest, rich forest and poor forest as in our study, so the data are incomplete and have no much helpful to assess the status and quality of mangroves. Therefore, this study also recommends that the assessment and monitoring of mangroves should be done together with the assessment of the area, quality and structure of mangroves because when there is sufficient information, such as on area and structures, it is meaningful to the silviculturist.

The results from this study are clear proof that the mangroves in Can Gio are well and successfully recovered since being completely destroyed by the spraying of herbicides and other chemical agents by the US military (1961-1965), through data from Landsat satellite images series of the periods (1972-2020) and it is being well managed.

At present, most of the mangrove area in the Can Gio Biosphere Reserve is over 40 years old, with very high tree density, but not once thinned as required by silvicultural measures. As a consequence, the trees do not receive enough nutrients and adequate living spaces, and diseases and pests, such as the anobium borer, lead to the deterioration of the quality of mangroves. Therefore, thinning is a necessary silvicultural measure to facilitate good forest growth at this time.

Today, there is increasing advancement in technology, satellites, sensors, so expanded accessibility of remotely sensed data with other high temporal and resolution imagery. Some are available for free, with strong computer systems, so satellite image processing speed quickly can completely meet the above requirements. Therefore, we propose to conduct mangrove monitoring in this study area with a frequency of once time per year.

Although, mangrove ecosystems that differ in their location of distribution will differ in terms of salinity, depth and flow regime, etc. However, according to some studies of 
Ross (1974), Lugo et al. (1974), Salem et al. (2012), FAO (2020), the mangrove forests of South Vietnam are similar, or nearly so, in their species composition to the wellknown mangrove communities of Malaysia, Indonesia, Australia, Africa, Mexico and the United States. So, we hope the results of this study are not just crucial for this study area, which is the Can Gio Biosphere Reserve, Vietnam but also be suggestive for other regions of the world with similar natural conditions for better management, monitoring and conservation along with sustainable development of mangrove forests.

Acknowledgments. The authors are grateful to project No. VAST01.07/20-21 from the Vietnam Academy of Science and Technology (VAST) for financial support of this research.

\section{REFERENCES}

[1] Anys, H., Bannari, A., He, D. C., Morin, D. (1994): Texture analysis for the mapping of urban areas using airborne MEIS-II images. - In: Proceedings of the First International Airborne Remote Sensing Conference and Exhibition (Vol. 3, pp. 231-245). Environmental Research Institute of Michigan.

[2] Brown, B., Fadillah, R., Nurdin, Y., Soulsby, I., Ahmad, R. (2014): Case study: Community Based Ecological Mangrove Rehabilitation (CBEMR) in Indonesia. From small (12-33 ha) to medium scales (400 ha) with pathways for adoption at larger scales (>5000 ha). - SAPIENS (Surveys and Perspectives Integrating Environment and Society) $7(2)$.

[3] Cao, H. B. (2007): Nghiên cứu khả năng hấp thụ $\mathrm{CO}_{2}$ của quần thể Dà quánh (Ceriops decandra Dong Hill) tự nhiên tại Khu dữ trữ sinh quyển rừng ngập mặn Cần Giờ (Original)/Study on $\mathrm{CO}_{2}$ squestration capacity of Ceriops decandra Dong Hill Can Gio Mangrove Biosphere Reserve. - Ho Chi Minh City, Minh (Translated by Luong, V. N).

[4] Chander, G., Markham, B. L., Helder, D. L. (2009): Summary of current radiometric calibration coefficients for Landsat MSS, TM, ETM+, and EO-1 ALI sensors. - Remote Sensing of Environment 113(5): 893-903.

[5] Chen, Y. C., Shih, C. H. (2019): Sustainable management of coastal wetlands in Taiwan: a review for invasion, conservation, and removal of mangroves. - Sustainability 11(16): 4305.

[6] Chen, B., Xiao, X., Li, X., Pan, L., Doughty, R., Ma, J., ... Sun, R. (2017): A mangrove forest map of China in 2015: Analysis of time series Landsat 7/8 and Sentinel-1A imagery in Google Earth Engine cloud computing platform. - ISPRS Journal of Photogrammetry and Remote Sensing 131: 104-120.

[7] Clough, B. F., Scott, K., (1989): Allometric relationships for estimating aboveground biomass in six mangrove species. - Forest Ecol. Manage. 27: 117-127.

[8] Cougo, M., Souza-Filho, P., Silva, A., Fernandes, M., Santos, J., Abreu, M., ... Simard, M. (2015): Radarsat-2 backscattering for the modeling of biophysical parameters of regenerating mangrove forests. - Remote Sensing 7(12): 17097-17112.

[9] Crippen, R. E. (1990): Calculating the vegetation index faster. - Remote Sensing of Environment 34(1): 71-73.

[10] Cuong, V. V. (1964): Flore et Vegetation de la Mangrove dela Region Saigon-cap Saint Jacques sud Viet-nam. - Ph.D. dissertation, University of Paris, France.

[11] De Leon, R. O. D., White, A. T. (1999): Mangrove Rehabilitation in the Philippines. - In: Streever, W. (ed.) An International Perspective on Wetland Rehabilitation. Springer, Dordrecht, pp. 37-42. 
[12] DeFries, R., Hansen, M., Townshend, J. (1995): Global discrimination of land cover types from metrics derived from AVHRR pathfinder data. - Remote Sensing of Environment 54(3): 209-222.

[13] Diele, K., Ngoc, D. T., Geist, S. J., Meyer, F. W., Pham, Q. H., Saint-Paul, U., ... Berger, U. (2013): Impact of typhoon disturbance on the diversity of key ecosystem engineers in a monoculture mangrove forest plantation, Can Gio Biosphere Reserve, Vietnam. Global and Planetary Change 110: 236-248.

[14] Donato, D. C., Kauffman, J. B., Murdiyarso, D., Kurnianto, S., Stidham, M., Kanninen, M. (2011): Mangroves among the most carbon-rich forests in the tropics. - Nature Geoscience 4: 293-297.

[15] Duke, N. C., Meynecke, J.-O., Dittmann, S., Ellison, A. M., Anger, K., Berger, U., Cannicci, S. et al. (2007): A world without mangroves? - Science 317(5834): 41-42.

[16] Falk, R. A. (2015): Environmental Warfare and Ecocide. - In: Falk, R. A. (ed.) The Vietnam War and International Law. Vol. 4. Princeton University Press, Princeton, NJ, pp. 287-303.

[17] FAO (2020): Mangrove management. - http://www.fao.org/forestry/mangrove/en/.

[18] Fitzgerald, R. W., Lees, B. G. (1994): Assessing the classification accuracy of multisource remote sensing data. - Remote sensing of Environment 47(3): 362-368.

[19] Fromard, F., Puig, H., Mougin, E., Marty, G., Betoulle, J. L., Cadamuro, L. (1998): Structure above-ground biomass and dynamics of mangrove ecosystems: new data from French Guiana. - Oecologia 115: 39-53.

[20] Giesen, W., Wulffraat, S., Zieren, M., Scholten, L. (2007): Mangrove Guidebook for Southeast Asia. - FAO, Rome.

[21] Giri, C. (2016): Observation and monitoring of mangrove forests using remote sensing: opportunities and challenges. - Remote Sensing 8(9): 783.

[22] Giri, C., Pengra, B., Zhu, Z., Singh, A., Tieszen, L. L. (2007): Monitoring mangrove forest dynamics of the Sundarbans in Bangladesh and India using multi-temporal satellite data from 1973 to 2000. - Estuarine, Coastal and Shelf Science 73(1-2): 91-100.

[23] Goldberg, L., Lagomasino, D., Thomas, N., Fatoyinbo, T. (2020): Global declines in human-driven mangrove loss. - Global Change Biology 26(10): 5844-5855.

[24] Green, E. P., Clark, C. D., Mumby, P. J., Edwards, A. J., Ellis, A. C. (1998): Remote sensing techniques for mangrove mapping. - International Journal of Remote Sensing 19(5): 935-956.

[25] Guo, M., Li, J., Sheng, C., Xu, J., Wu, L. (2017): A review of wetland remote sensing. Sensors 17(4): 777.

[26] Ha'apio, M. O., Leal Filho, W., Wairiu, M. (2018): A 'Cost Barrier' Perspective to Adaptation on a Coral Triangle Initiative (CTI) and Mangrove Rehabilitation Projects (MRP) in Solomon Islands. - In: Filho, W. L., Nalau, J. (eds.) Limits to Climate Change Adaptation. Springer, Cham, pp. 325-343.

[27] Haas, R. H., Deering, D. W., Rouse, J. W., Schell, J. A. (1975): Monitoring vegetation conditions from Landsat for use in range management. - NASA Earth Resources Survey Symposium Proc., Houston, Texas, June 1975. Vol. 1, pp. 43-52.

[28] Hai, N. T., Dell, B., Phuong, V. T., Harper, R. J. (2020): Towards a more robust approach for the restoration of mangroves in Vietnam. - Annals of Forest Science 77(1): 1-18.

[29] Haralick, R. M., Shanmugam, K., Dinstein, I. H. (1973): Textural features for image classification. - IEEE Transactions on Systems, Man, and Cybernetics 6: 610-621.

[30] Hoan, H. D., Sinh, L. V., Trung, P. V., Sơn, Đ. V. (2009): Nghiên cứu khả năng tích trữ carbon của rừng trồng Lumnitzera racemosa WILLD tại Khu dự trữ sinh quyển rừng ngập mặn Can Gio, Thành phố Hồ Chí Minh (Original)/Study on carbon storage capacity of Lumnitzera racemosa WILLD plantations at Can Gio Mangrove Biosphere Reserve. - Ho Chi Minh City, Minh (Translated by Luong V. N).

[31] Hong, P. N. (2001): Reforestation of mangroves after severe impacts of herbicides during the Viet Nam war: the case of Can Gio. - Unasylva 52(207): 57-60. 
[32] Hong, P. N., San, H. T. (1993): Mangroves of Vietnam. - IUCN, Bangkok, Thailand.

[33] Hong, P. N. (ed.), Quynh, B. N., Tri, H. N. (1988): Rừng ngập mặn (Rừng sát). Tiềm năng và sử dụng. Nhà xuất bản nông nghiệp năm 1988 (Original). Mangrove Forest (Rung sat). Potential and Use. - Agricultural Publishing House, Hanoi (translated by Luong, V. N).

[34] Hong P. N., Nam, V. N., San, T. H., Tang, T. T., Tre, T. L., Tri, H. N., Tuan, S. M., Tuan, X. L. (1999): Rừng ngập mặn Việt Nam. Nhà xuất bản nông nghiệp Hà Nội năm 1999 (Original). Mangrove Forest of Vietnam. - Agricultural Publishing House, Hanoi (Translated by Luong, V. N).

[35] Hong, S. H., Kim, H. O., Wdowinski, S., Feliciano, E. (2015): Evaluation of polarimetric SAR decomposition for classifying wetland vegetation types. - Remote Sensing 7(7): $8563-8585$.

[36] IPCC (2003): Good Practice Guidance for Land Use, Land-Use Change and Forestry. IPCC National Greenhouse Gas Inventories Programme Technical Support Unit, Hayama, Japan.

[37] Jager, G., Benz, U. (2000): Measures of classification accuracy based on fuzzy similarity. - IEEE Transactions on Geoscience and Remote Sensing 38(3): 1462-1467.

[38] JAXA (2014): ALOS-2/Calibration Result of JAXA Standard Products. - Japan Aerospace Exploration Agency, Earth Observation Research Center, Tsukuba, Japan.

[39] Kamal, M., Phinn, S., Johansen, K. (2016): Assessment of multi-resolution image data for mangrove leaf area index mapping. - Remote Sensing of Environment 176: 242-254.

[40] Kamthonkiat, D., Rodfai, C., Saiwanrungkul, A., Koshimura, S., Matsuoka, M. (2011): Geoinformatics in mangrove monitoring: damage and recovery after the 2004 Indian Ocean tsunami in Phang Nga, Thailand. - Natural Hazards and Earth System Sciences 11(7): 1851-1862.

[41] Komiyama, A., Poungparn, S. Kato, S. (2005): Common allometric equations for estimating the tree weight of mangroves. - Journal of Tropical Ecology 21(04): 471-477. DOI: $10.1017 / \mathrm{S} 0266467405002476$.

[42] Koniuszewski, A. (2016): Land Degradation from Military Toxics: Public Health Considerations and Possible Solution Paths. - In: Chabay, I. et al. (eds.) Land Restoration. Academic Press, Cambridge, MA, pp. 119-131.

[43] Kovacs, J. M., Lu, X. X., Flores-Verdugo, F., Zhang, C., de Santiago, F. F., Jiao, X. (2013): Applications of ALOS PALSAR for monitoring biophysical parameters of a degraded black mangrove (Avicennia germinans) forest. - ISPRS Journal of Photogrammetry and Remote Sensing 82: 102-111.

[44] Kuenzer, C., Bluemel, A., Gebhardt, S., Quoc, T. V., Dech, S. (2011): Remote sensing of mangrove ecosystems: a review. - Remote Sensing 3(5): 878-928.

[45] Le Toan, T., Beaudoin, A., Riom, J., Guyon, D. (1992): Relating forest biomass to SAR data. - IEEE Transactions on Geoscience and Remote Sensing 30(2): 403-411.

[46] Lewis III, R. R. (2005): Ecological engineering for successful management and restoration of mangrove forests. - Ecological Engineering 24(4): 403-418.

[47] Long, J. B., Giri, C. (2011): Mapping the Philippines' mangrove forests using Landsat imagery. - Sensors 11(3): 2972-2981.

[48] Lucas, R., Van De Kerchove, R., Otero, V., Lagomasino, D., Fatoyinbo, L., Omar, H., ... Dahdouh-Guebas, F. (2020): Structural characterisation of mangrove forests achieved through combining multiple sources of remote sensing data. - Remote Sensing of Environment 237: 111543.

[49] Lugo, A. E., Snedaker, S. C. (1974): The ecology of mangroves. - Annual Review of Ecology and Systematics 5(1): 39-64.

[50] Luong, N. V., Tateishi, R., Hoan, N. T. (2015): Analysis of an impact of succession in mangrove forest association using remote sensing and GIS technology. - Journal of Geography and Geology 7(1): 106. 
[51] Luong, V. N., Tateishi, R., Kondoh, A., Sharma, R. C., Thanh Nguyen, H., Trong To, T., Ho Tong Minh, D. (2016): Mapping tropical forest biomass by combining ALOS-2, Landsat 8, and field plots data. - Land 5(4): 31.

[52] Luong V. N., Tu, T. T., Khoi, A. K., Hong, X. T., Thuy, T. T. L. (2019): Biomass Estimation and Mapping of Can Gio Mangrove Biosphere Reserve in South of Viet Nam using ALOS-2 PALSAR-2 data. - Applied Ecology and Environmental Research 17(1): 15-31.

[53] MacDonald, T. A. (1999): Wetland Rehabilitation and Remote Sensing. - In: Streever, W. (ed.) An International Perspective on Wetland Rehabilitation. Springer, Dordrecht, pp. 251-264.

[54] Marchand, M. (2008): Mangrove restoration in Vietnam: key considerations and a practical guide. $\quad-\quad$ http://resolver.tudelft.nl/uuid:98b5ba43-1452-4631-81dcad043ef3992c.

[55] MARD (2015): Announcing the current forest status of Vietnam in 2015. - Decision No. 3158 / QD-BNN-TCLN dated July 27, 2016.

[56] MARD (2018): Criteria for forest classification in Vietnam, Ministry of Agriculture and Rural Development. - Circular No. 34/2009/TT-BNNPTNT.

[57] Mougin, E., Proisy, C., Marty, G., Fromard, F., Puig, H., Betoulle, J. L., Rudant, J. P. (1999): Multifrequency and multipolarization radar backscattering from mangrove forests. - IEEE Transactions on Geoscience and Remote Sensing 37(1): 94-102.

[58] Murdiyarso, D., Purbopuspito, J., Kauffman, J. B., Warren, M. W., Sasmito, S. D., Donato, D. C., ... Kurnianto, S. (2015): The potential of Indonesian mangrove forests for global climate change mitigation. - Nature Climate Change 5(12): 1089-1092.

[59] Nam, V. N., Sinh, L. V., Miyagi, T., Baba, S., Chan, H. T. (2014): An overview of Can Gio district and mangrove biosphere reserve. - Studies in Can Gio Mangrove Biosphere Reserve, Ho Chi Minh City, Vietnam Mangrove Ecosystems Technical Reports 6: 1-7.

[60] Nesha, M. K., Hussin, Y. A., van Leeuwen, L. M., Sulistioadi, Y. B. (2020): Modeling and mapping aboveground biomass of the restored mangroves using ALOS-2 PALSAR-2 in East Kalimantan, Indonesia. - International Journal of Applied Earth Observation and Geoinformation 91: 102158.

[61] Nguyen, L. V., To, T. T., Trinh, H. X., Hoang, T. T. L. (2018): The analysis of mangrove forest changes period of 20 years in Can Gio Biosphere Reserve, Viet Nam using remote sensing and GIS technology. - Biosphere Reserves 6.

[62] Nham Tuyet, L. T., Johansson, A. (2001): Impact of chemical warfare with agent orange on women's reproductive lives in Vietnam: a pilot study. - Reproductive Health Matters 9(18): 156-164.

[63] Ong, J. E., Gong, W. K., Wong, C. H. (2004): Allometry and partitioning of the mangrove, Rhizophora apiculata. - Forest Ecology and Management 188(1-3): 395-408.

[64] Oostdijk, M., Santos, M. J., Whigham, D., Verhoeven, J., Silvestri, S. (2018): Assessing rehabilitation of managed mangrove ecosystems using high resolution remote sensing. Estuarine, Coastal and Shelf Science 211: 238-247.

[65] Pham, T. D., Yokoya, N., Bui, D. T., Yoshino, K., Friess, D. A. (2019): Remote sensing approaches for monitoring mangrove species, structure, and biomass: opportunities and challenges. - Remote Sensing 11(3): 230.

[66] Pham, T. D., Le, N. N., Ha, N. T., Nguyen, L. V., Xia, J., Yokoya, N., ... \& Takeuchi, W. (2020). Estimating mangrove above-ground biomass using extreme gradient boosting decision trees algorithm with fused sentinel-2 and ALOS-2 PALSAR-2 data in can Gio biosphere reserve, Vietnam. Remote Sensing, 12(5), 777.

[67] Pham, M. H., Do, T. H., Pham, V. M., Bui, Q. T. (2020): Mangrove forest classification and aboveground biomass estimation using an atom search algorithm and adaptive neurofuzzy inference system. - Plos One 15(5): e0233110.

[68] Potapov, P., Hansen, M. C., Kommareddy, I., Kommareddy, A., Turubanova, S., Pickens, A., ... Ying, Q. (2020): Landsat analysis ready data for global land cover and land cover change mapping. - Remote Sensing 12(3): 426. 
[69] Primavera, J. H., Esteban, J. M. A. (2008): A review of mangrove rehabilitation in the Philippines: successes, failures and future prospects. - Wetlands Ecology and Management 16(5): 345-358.

[70] Ross, P. (1974): The Effects of Herbicides in South Vietnam. Part B. Working Papers: The Effects of Herbicides on the Mangrove of South Vietnam. - National Academy of Sciences-National Research Council, Washington, DC.

[71] Rouse, J. W., Haas, R. H., Schell, J. A., Deering, D. W. (1974): Monitoring vegetation systems in the Great Plains with ERTS. - NASA Special Publication 351(1974): 309.

[72] Salem, M. E., Mercer, D. E. (2012): the economic value of mangroves: a meta-analysis. Sustainability 4: 359-383.

[73] Schecter, A., Dai, L. C., Thuy, L. T., Quynh, H. T., Minh, D. Q., Cau, H. D., ... Baughman, R. (1995): Agent Orange and the Vietnamese: the persistence of elevated dioxin levels in human tissues. - American Journal of Public Health 85(4): 516-522.

[74] Seto, K. C., Fragkias, M. (2007): Mangrove conversion and aquaculture development in Vietnam: a remote sensing-based approach for evaluating the Ramsar Convention on Wetlands. - Global Environmental Change 17(3-4): 486-500.

[75] Thai, V. T. (1998): Tropical Forest Ecosystems in Vietnam. Chapter IV. - Science and Technology Publishing House, Hanoi.

[76] Thomas, W. L. (1974): The Effects of Herbicides in South Vietnam. Part B. Working Papers: Economic Stress and Settlement Changes. - National Academy of SciencesNational Research Council, Washington, DC.

[77] Thuy, H. L. T., Tan, M. T., Van, T. T. T., Bien, L. B., Ha, N. M., Nhung, N. T. (2020): Using Sentinel image data and plot survey for the assessment of biomass and carbon stock in coastal forests of Thai Binh Province, Vietnam. - Applied Ecology and Environmental Research 18(6): 7499-7514.

[78] Tri, N. H., Hong, P. N., Manh, M. N. T., Tuan, M. L. X., Anh, M. P. H., Tho, M. N. H., ... Tuan, M. L. D. (2000): Valuation of the mangrove ecosystem in Can Gio mangrove biosphere reserve, Vietnam. - UNESCO/MAB Project, Final Report, Hanoi.

[79] Tuan, D. L., Oanh, T. K. T., Thanh, V. C., Quy, D. N. (2002): Can Gio Mangrove Biosphere Reserve. - Agricultural Publishing House, Hanoi.

[80] UNESCO (1973): International Classification and Mapping of Vegetation. - United Nations Educational, Scientific and Cultural Organization, Paris.

[81] Vaiphasa, C. (2006): Remote sensing techniques for mangrove mapping. - Thesis for the degree of Doctor, Wageningen University, The Netherlands.

[82] Valderrama-Landeros, L., Flores-de-Santiago, F., Kovacs, J. M., Flores-Verdugo, F. (2018): An assessment of commonly employed satellite-based remote sensors for mapping mangrove species in Mexico using an NDVI-based classification scheme. Environmental Monitoring and Assessment 190(1): 1-13.

[83] Veettil, B. K., Ward, R. D., Quang, N. X., Trang, N. T. T., Giang, T. H. (2019): Mangroves of Vietnam: historical development, current state of research and future threats. - Estuarine, Coastal and Shelf Science 218: 212-236.

[84] Vo Van Hong và nnk (2006): Công tác điều tra rừng tại Việt Nam/Forest Inventory Work in Vietnam. - Ministry of Agriculture and Rural Development, Hanoi.

[85] Vo, T. Q., Künzer, C., Oppelt, N. (2015): How remote sensing supports mangrove ecosystem service valuation: a case study in Ca Mau province, Vietnam. - Ecosystem Services 14: 67-75.

[86] Wang, L., Jia, M., Yin, D., Tian, J. (2019): A review of remote sensing for mangrove forests: 1956-2018. - Remote Sensing of Environment 231: 111223.

[87] Westing, A. H. (1983): The environmental aftermath of warfare in Viet Nam. - Natural Resources Journal 23(2): 365-389.

[88] Xie, Y., Sha, Z., Yu, M. (2008): Remote sensing imagery in vegetation mapping: a review. - Journal of Plant Ecology 1(1): 9-23. 